\title{
Changes in the Ventilation of the Oxygen Minimum Zone of the Tropical North Atlantic
}

\author{
Peter Brandt, Verena Hormann, Arne Körtzinger, Martin Visbeck, \\ GERD KRAHMANN, AND LOTHAR STRAMMA \\ IFM-GEOMAR, Leibniz-Institut für Meereswissenschaften, Kiel, Germany \\ RicK LUMPKIN AND CLAUDIA SCHMID \\ NOAA/AOML/Physical Oceanography Division, Miami, Florida
}

(Manuscript received 17 June 2009, in final form 23 February 2010)

\begin{abstract}
Changes in the ventilation of the oxygen minimum zone (OMZ) of the tropical North Atlantic are studied using oceanographic data from 18 research cruises carried out between $28.5^{\circ}$ and $23^{\circ} \mathrm{W}$ during $1999-2008$ as well as historical data referring to the period 1972-85. In the core of the OMZ at about 400-m depth, a highly significant oxygen decrease of about $15 \mu \mathrm{mol} \mathrm{kg}{ }^{-1}$ is found between the two periods. During the same time interval, the salinity at the oxygen minimum increased by about 0.1 . Above the core of the OMZ, within the central water layer, oxygen decreased too, but salinity changed only slightly or even decreased. The scatter in the local oxygen-salinity relations decreased from the earlier to the later period suggesting a reduced filamentation due to mesoscale eddies and/or zonal jets acting on the background gradients. Here it is suggested that latitudinally alternating zonal jets with observed amplitudes of a few centimeters per second in the depth range of the OMZ contribute to the ventilation of the OMZ. A conceptual model of the ventilation of the OMZ is used to corroborate the hypothesis that changes in the strength of zonal jets affect mean oxygen levels in the OMZ. According to the model, a weakening of zonal jets, which is in general agreement with observed hydrographic evidences, is associated with a reduction of the mean oxygen levels that could significantly contribute to the observed deoxygenation of the North Atlantic OMZ.
\end{abstract}

\section{Introduction}

Oxygen minimum zones (OMZs) are present in the eastern tropical oceans between 100 and 700-m depth (e.g., Karstensen et al. 2008). These zones are caused by a combination of weak ventilation responsible for the shadow zones of the ventilated thermocline (Luyten et al. 1983) and elevated oxygen consumption due to enhanced respiration, a consequence of their proximity to coastal upwelling regions that are hotspots of biological productivity. The recently reported expansion of OMZs in the World Ocean (Stramma et al. 2008b) has, in large ocean areas, major implications for biogeochemical cycles, particularly those of carbon and nitrogen, and might also have adverse effects on ecosystem function and

Corresponding author address: Peter Brandt, IFM-GEOMAR, Leibniz-Institut für Meereswissenschaften, Düsternbrooker Weg 20, 24105 Kiel, Germany.

E-mail: pbrandt@ifm-geomar.de services (Chan et al. 2008; Keeling et al. 2010). As proposed by Joos et al. (2003) and confirmed in a recent review by Keeling et al. (2010), deoxygenation can now be regarded as a near-ubiquitous feature of all ocean basins that is indicative of the effects of global warming. Although the science of ocean deoxygenation is still in its infancy, a clear convergence of observational and model evidence suggests that more significant changes are looming. These effects are further aggravated by concurrent oceanic invasion of anthropogenic $\mathrm{CO}_{2}$, which further tightens the limits to marine life (Brewer and Peltzer 2009).

Despite the potentially serious consequences of ocean deoxygenation, the physical and/or biogeochemical processes that are responsible for the observed changes in the oxygen content of the OMZs are largely unknown. There are several possible explanations how anthropogenic forcing can cause a decrease in the oxygen content. Among them are: (i) an increase in heterotrophic respiration along the pathways of ventilating water masses 
due to excess organic carbon formed at higher $\mathrm{CO}_{2}$ levels (Oschlies et al. 2008), (ii) an increase of organic matter oxidization in shallow waters due to reduction of mineralballast fluxes (Hofmann and Schellnhuber 2009), (iii) an increased stratification and a corresponding reduction of ventilation, or (iv) solubility changes associated with a warming of subducted water masses (Bopp et al. 2002; Matear and Hirst 2003). However, a recent study by Gnanadesikan et al. (2007) showed using a simple advection-diffusion model that with increased stratification and resulting reduced ventilation the average water mass age within the OMZ can still decrease. This counterintuitive result, which emerged from a changed relative contribution of old deep waters and young near-surface waters, points toward the importance of different processes, such as vertical and lateral mixing, for local oxygen balances. Recently observed oxygen changes in the subtropical and subpolar water masses of the North Atlantic Ocean have mainly been attributed to changes in circulation and water mass properties associated with decadal changes of the North Atlantic Oscillation (Johnson and Gruber 2007), the primary climate mode of the Northern Hemisphere. Stramma et al. (2008b) showed that there are substantial differences between the oxygen changes within the OMZs of the World Ocean. The oxygen trend of $-0.34 \pm 0.13 \mu \mathrm{mol} \mathrm{kg} \mathrm{yr}^{-1}$ in the 300-to-700-m layer of the North Atlantic OMZ is twice as large as trends obtained for the OMZs of the South Atlantic, Pacific, and Indian oceans (Stramma et al. 2008b). Thus, there might be different processes contributing to the deoxygenation of the OMZs in the different ocean basins.

The velocity field in the tropical Atlantic Ocean is characterized by vigorous surface and thermocline current branches (Fig. 1). Among them are the North Equatorial Current (NEC), northern and central branches of the South Equatorial Current (nSEC; cSEC), the North Equatorial Countercurrent (NECC), its northern branch (nNECC), the North Brazil Current (NBC), the North and South Equatorial Undercurrents (NEUC; SEUC), and the Equatorial Undercurrent (EUC). Below the thermocline, the flow is generally weaker. Near-equatorial observations revealed the existence of a mean westward flow at the equator, the Equatorial Intermediate Current (EIC), and eastward current branches near $2^{\circ} \mathrm{N}$ and $2^{\circ} \mathrm{S}$, the Northern and Southern Intermediate Countercurrents (NICC; SICC), respectively (Tsuchiya et al. 1992; Schott et al. 1995; Boebel et al. 1999; Bourlès et al. 2002; Brandt et al. 2006, 2008). More recently, it became evident that these zonal current branches are part of a system of multiple latitudinally alternating zonal jets with meridional wavelengths of $2^{\circ}-4^{\circ}$ latitude. The direct observation of these jets at intermediate depths within the

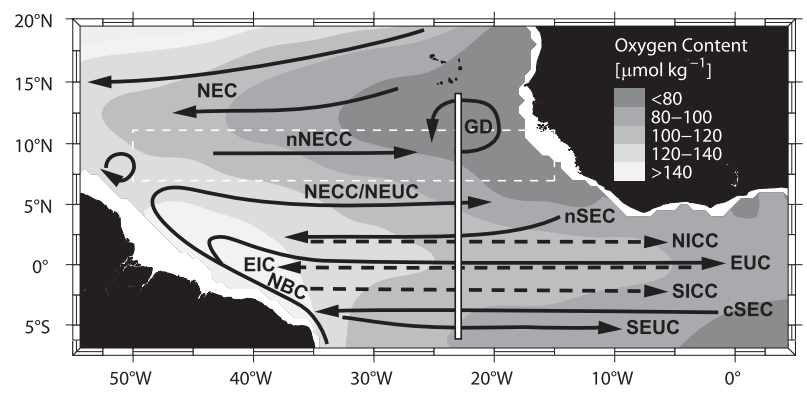

FIG. 1. Schematic diagram of the shallow subtropical and tropical Atlantic circulation superimposed on the WGHC distribution of oxygen concentration $\left(\mu \mathrm{mol} \mathrm{kg}{ }^{-1}\right.$ ) at 300-500-m depth (after Brandt et al. 2008). The model domain is indicated by the white dashed rectangle. Also shown is the location of the meridional shipboard current profiling section along $23^{\circ} \mathrm{W}$ (white solid). Surface and thermocline current branches shown (black solid arrows) are NEC, nSEC, cSEC, NECC, NBC, NEUC, SEUC, EUC, and the cyclonic circulation around the Guinea Dome (GD). Intermediate current branches shown (black dashed arrows) are NICC, SICC, and EIC.

$\mathrm{OMZ}$ is hindered because of dominant eddy motions in the region. However, their existence has been verified using global altimetry (Maximenko et al. 2005) as well as with subsurface floats drifting near 800- and 1000-m depths in the tropical Atlantic (Ollitrault et al. 2006). These jets, which are believed to be generated by the eddy field in the presence of a planetary potential vorticity gradient, are also reproduced in high-resolution models of the Pacific (Nakano and Hasumi 2005; Richards et al. 2006) and Atlantic oceans (Eden 2006).

Both latitudinally alternating zonal jets and eddy fluxes contribute to the isopycnal ventilation of the OMZ in the eastern tropical North Atlantic. While eastward jets transport high-oxygen waters from the western boundary toward the OMZ, the relative importance of zonal and meridional eddy fluxes depends on the anisotropy of both horizontal eddy diffusivities and horizontal oxygen gradients (Fig. 1). Here we analyze long-term changes in the hydrographic fields and the associated geostrophic flow between the periods $1972-85$, a period characterized by particularly good data coverage, and 1999-2008 and relate them to possible changes in the ventilation of the OMZ.

After describing the available data used for this study in section 2, the mean and variability of currents and hydrographic properties for the period 1999-2008 are discussed in section 3. Changes in the zonal flow field and hydrographic properties between 1972-85 and 19992008 are investigated in section 4. In section 5, we present a conceptual model for the ventilation and oxygen consumption in the OMZ. This model is aimed at corroborating a new hypothesis, in which the mean oxygen level in the $\mathrm{OMZ}$ is affected by changes in the strength of 
TABLE 1. Research cruise data analyzed in this study: name of the research vessel, date of the cruise, mean longitude and latitudinal extent, depth range, and measurements used here [vessel-mounted acoustic Doppler current profiler (VM-ADCP); lowered ADCP (L-ADCP); conductivity-temperature-depth (CTD) probe; CTD oxygen $\left(\mathrm{CTD} / \mathrm{O}_{2}\right)$ probe]. Name of the research vessel and date of the cruise are marked in boldface for research cruises along $24^{\circ}-23^{\circ} \mathrm{W}$.

\begin{tabular}{|c|c|c|c|}
\hline Cruise & Section & Max depth (m) & Measurements \\
\hline Thalassa (August 1999) & $6^{\circ} \mathrm{S}-6^{\circ} \mathrm{N}, 23^{\circ} \mathrm{W}$ & Bottom & VM-ADCP, L-ADCP, CTD/O \\
\hline Seward Johnson (January 2000) & $6^{\circ} \mathrm{S}-4^{\circ} \mathrm{N}, 23^{\circ} \mathrm{W}$ & 2000 & L-ADCP, CTD \\
\hline Seward Johnson (January 2000) & $6^{\circ} \mathrm{S}-4^{\circ} \mathrm{N}, 25.5^{\circ} \mathrm{W}$ & 2000 & L-ADCP, CTD \\
\hline Seward Johnson (January 2000) & $6^{\circ} \mathrm{S}-0^{\circ}, 28^{\circ} \mathrm{W}$ & 2000 & L-ADCP, CTD \\
\hline Meteor 47/1 (April 2000) & $5^{\circ} \mathrm{S}-4^{\circ} \mathrm{N}, 23^{\circ} \mathrm{W}$ & Bottom & VM-ADCP, L-ADCP, CTD/O ${ }_{2}$ \\
\hline Meteor 53/2 (May 2002) & $11.5^{\circ} \mathrm{S}-2.5^{\circ} \mathrm{N}, 28^{\circ} \mathrm{W}$ & 5000 & VM-ADCP, L-ADCP, CTD/O \\
\hline Meteor 55 (October 2002) & $0^{\circ}-10^{\circ} \mathrm{N}, 24^{\circ} \mathrm{W}$ & 650 & VM-ADCP, CTD \\
\hline Sonne 170 (May 2003) & $11.5^{\circ}-2.5^{\circ} \mathrm{S}, 28.5^{\circ} \mathrm{W}$ & 1300 & VM-ADCP, L-ADCP, CTD/O ${ }_{2}$ \\
\hline Ron Brown (August 2003) & $6^{\circ} \mathrm{S}-10^{\circ} \mathrm{N}, \sim 27^{\circ} \mathrm{W}$ & Bottom & VM-ADCP, L-ADCP, CTD $/ \mathrm{O}_{2}$ \\
\hline Meteor 62/2 (August 2004) & $5^{\circ} \mathrm{S}-2^{\circ} \mathrm{N}, 28^{\circ} \mathrm{W}$ & 1400 & VM-ADCP, L-ADCP, CTD \\
\hline Polarstern ANT XXII/5 (June 2005) & $20^{\circ} \mathrm{S}-20^{\circ} \mathrm{N}, 23^{\circ} \mathrm{W}$ & 300 & VM-ADCP \\
\hline Meteor 68/1 (May 2006) & $2^{\circ} \mathrm{S}-0.5^{\circ} \mathrm{N}, \sim 23^{\circ} \mathrm{W}$ & 500 & VM-ADCP \\
\hline Ron Brown (June 2006) & $5^{\circ} \mathrm{S}-20^{\circ} \mathrm{N}, 23^{\circ} \mathrm{W}$ & $750 / 1500$ & VM-ADCP, CTD $/ \mathrm{O}_{2}$ \\
\hline Ron Brown (June-July 2006) & $5^{\circ} \mathrm{S}-14.5^{\circ} \mathrm{N}, 23^{\circ} \mathrm{W}$ & $750 / 1500$ & VM-ADCP, CTD $/ \mathrm{O}_{2}$ \\
\hline Meteor 68/2 (June-July 2006) & $4^{\circ} \mathrm{S}-15.25^{\circ} \mathrm{N}, 23^{\circ} \mathrm{W}$ & 1300 & VM-ADCP, CTD $/ \mathrm{O}_{2}$ \\
\hline Ron Brown (May 2007) & $4^{\circ}-20^{\circ} \mathrm{N}, 23^{\circ} \mathrm{W}$ & $750 / 1500$ & VM-ADCP, CTD $/ \mathrm{O}_{2}$ \\
\hline L'Atalante (February-March 2008) & $2^{\circ} \mathrm{S}-14^{\circ} \mathrm{N}, 23^{\circ} \mathrm{W}$ & 400 & VM-ADCP \\
\hline L'Atalante (March 2008) & $2^{\circ} \mathrm{S}-14^{\circ} \mathrm{N}, 23^{\circ} \mathrm{W}$ & 1300 & VM-ADCP, L-ADCP, CTD/O ${ }_{2}$ \\
\hline Merian 08/1 (April 2008) & $7^{\circ}-11.25^{\circ} \mathrm{N}, \sim 23^{\circ} \mathrm{W}$ & 1000 & $\mathrm{CTD} / \mathrm{O}_{2}$ \\
\hline Polarstern ANT XXIV/4 (April-May 2008) & $20^{\circ} \mathrm{S}-20^{\circ} \mathrm{N}, \sim 26^{\circ} \mathrm{W}$ & 250 & VM-ADCP \\
\hline Merian 08/1 (May 2008) & $8^{\circ}-14.75^{\circ} \mathrm{N}, \sim 25^{\circ} \mathrm{W}$ & 800 & VM-ADCP \\
\hline Merian 10/1 (November-December 2008) & $4^{\circ}-14^{\circ} \mathrm{N}, 23^{\circ} \mathrm{W}$ & $650 / 1000$ & VM-ADCP, CTD $/ \mathrm{O}_{2}$ \\
\hline
\end{tabular}

alternating zonal jets. Summary and discussion are presented in section 6 .

\section{Data}

For the period 1999-2008, we make use of current and hydrographic shipboard measurements obtained from various research cruises into the central tropical Atlantic (Table 1). An updated mean zonal velocity section between $28.5^{\circ}$ and $23^{\circ} \mathrm{W}$ is derived after Brandt et al. (2006). For direct current measurements, vessel mounted and lowered acoustic Doppler current profilers (ADCPs) have usually been in use. Accuracy of 1-h vessel-mounted ADCP averages is estimated to be better than $2-4 \mathrm{~cm} \mathrm{~s}^{-1}$ (Fischer et al. 2003) and the accuracy of lowered ADCP data is assumed to be better than $5 \mathrm{~cm} \mathrm{~s}^{-1}$ (Visbeck 2002). During postprocessing, all available current measurements are merged taking into account the higher accuracy and better horizontal resolution of the vessel mounted ADCP. For each section, the current and hydrographic data are mapped on a regular meridional $\left(0.05^{\circ}\right.$ latitude $)$ and vertical $(10 \mathrm{~m})$ grid using a Gaussian interpolation scheme. The respective mean sections ${ }^{1}$ are

\footnotetext{
${ }^{1}$ ADCP measurements yielded good-quality data only below $30 \mathrm{~m}$ and surface layer values are obtained as described in Brandt et al. (2006).
}

derived by averaging all existing data at each grid point, finally smoothed by a Gaussian filter [horizontal and vertical influence (cutoff) radii: $0.05^{\circ}\left(0.1^{\circ}\right)$ latitude and $10 \mathrm{~m}(20 \mathrm{~m})$, respectively]. When calculating the mean velocity field from a large number of velocity sections, the measurement error is believed to be small compared to the error of the mean velocity because of noise associated with oceanic fluctuations, such as, for example, the mesoscale eddy field and internal waves. Near the core of the $\mathrm{OMZ}$; that is, between $7^{\circ}$ and $11^{\circ} \mathrm{N}$ and between 300- and 500-m depth, the local standard deviation of the zonal velocity averages to $4.3 \mathrm{~cm} \mathrm{~s}^{-1}$, which yields a standard error of $1.4 \mathrm{~cm} \mathrm{~s}^{-1}$ for 8-12 independent measurements from the individual ship sections.

For the earlier period from 1972 to 1985 , we have assembled hydrographic profiles (salinity, potential temperature, and dissolved oxygen) measured within the region $0^{\circ}-14^{\circ} \mathrm{N}, 22^{\circ}-24^{\circ} \mathrm{W}$ (Table 2 ) from the database that was used to produce the World Ocean Circulation Experiment (WOCE) Global Hydrographic Climatology (WGHC; Gouretski and Koltermann 2004). The data accuracy, especially of the older datasets, can only be estimated. A substantial number of profiles was collected following the standards set by WOCE. Older profiles are likely to have achieved a lower accuracy. Overall we conservatively assume that the accuracy of any data point falls within twice the WOCE standard for water 
TABLE 2. Number of different $S$ and $\mathrm{O}_{2}$ profiles (obvious outliers removed) taken between $22^{\circ}$ and $24^{\circ} \mathrm{W}$ during $1972-85$ for $2^{\circ}$ latitude $\times 200$-m depth boxes.

\begin{tabular}{lllrlrrrr}
\hline Depth (m) & Profile & $0^{\circ}-2^{\circ}$ & $2^{\circ}-4^{\circ}$ & $4^{\circ}-6^{\circ}$ & $6^{\circ}-8^{\circ}$ & $8^{\circ}-10^{\circ}$ & $10^{\circ}-12^{\circ}$ & $12-14^{\circ} \mathrm{N}$ \\
\hline $0-200$ & $S$ & 294 & 139 & 505 & 772 & 1461 & 396 & 205 \\
& $\mathrm{O}_{2}$ & 197 & 88 & 206 & 72 & 146 & 207 & 128 \\
$200-400$ & $S$ & 284 & 138 & 501 & 615 & 1285 & 393 & 200 \\
& $\mathrm{O}_{2}$ & 189 & 87 & 200 & 71 & 146 & 204 & 123 \\
$400-600$ & $S$ & 276 & 136 & 479 & 607 & 1256 & 395 & 178 \\
& $\mathrm{O}_{2}$ & 183 & 83 & 184 & 70 & 145 & 205 & 101 \\
$600-800$ & $\mathrm{~S}$ & 186 & 47 & 267 & 119 & 404 & 344 & 140 \\
& $\mathrm{O}_{2}$ & 106 & 27 & 145 & 17 & 120 & 176 & 81 \\
$800-1000$ & $S$ & 167 & 45 & 254 & 110 & 368 & 326 & 120 \\
& $\mathrm{O}_{2}$ & 81 & 25 & 133 & 13 & 122 & 168 & 70 \\
\hline
\end{tabular}

samples; that is, $0.01^{\circ} \mathrm{C}, 0.004$, and $5 \mu \mathrm{mol} \mathrm{kg}{ }^{-1}$ for temperature, salinity, and dissolved oxygen, respectively.

To ensure a high data quality for the earlier period, obvious outliers are removed by visual inspection and a standard deviation criterion is applied for latitude (neutral density) $\left[1^{\circ}-2^{\circ}(0.1)\right]$ or latitude (depth) $\left[0.5^{\circ}\right.$ $(50 \mathrm{~m})$ ] boxes; that is, values deviating more than two standard deviations from a preliminary box median are excluded. In addition, the distribution of hydrographic properties along different sections is taken from the relatively smooth climatology obtained by Gouretski and Koltermann (2004), hereinafter referred to as WGHC.

While we use data from ship sections between $28.5^{\circ}$ and $23^{\circ} \mathrm{W}$ for the general description of velocity and hydrographic fields, we use only data acquired between $22^{\circ}$ and $24^{\circ} \mathrm{W}$ for the analysis of trends and variability of hydrographic properties (see Table 1). This narrowing of the region is necessary to avoid biases due to the presence of zonal gradients in the distribution of hydrographic properties, particularly oxygen and salinity.

\section{Circulation and hydrographic fields}

\section{a. Mean}

The mean circulation in the central tropical Atlantic as obtained from research cruises performed along meridional sections between $28.5^{\circ}$ and $23^{\circ} \mathrm{W}$ during the period 1999-2008 (Table 1) is characterized by narrow east- and westward current bands (or jets; Fig. 2a). Because of the large-scale mean east-west gradient in the dissolved oxygen concentration in the central and intermediate water layers (see Fig. 1), eastward currents are generally associated with higher oxygen concentrations than westward currents (Figs. 2a,b; Brandt et al. 2008; Stramma et al. 2008a). The salinity distribution in this area (Fig. 2c) is characterized by a subsurface maximum defining the Subtropical Underwater (between the
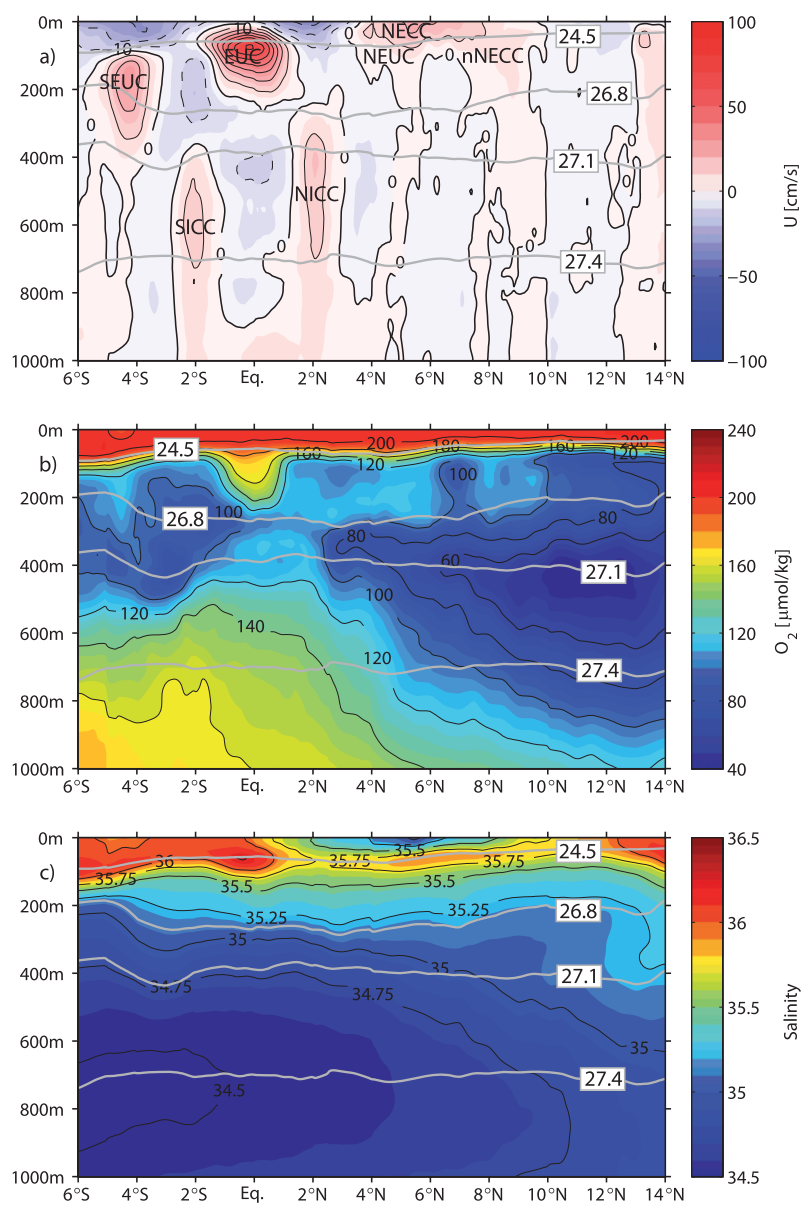

FIG. 2. (a) Mean zonal velocity, (b) oxygen content, and (c) salinity as obtained from meridional ship sections taken between $28.5^{\circ}$ and $23^{\circ} \mathrm{W}$ during $1999-2008$. Eastward current bands, marked by reddish colors, are generally associated with elevated oxygen content. Gray lines mark $\gamma_{n}$. At $\gamma_{n}=27.1$, which corresponds to the core of the OMZ, highest oxygen content is found in the equatorial region.

surface and about $100 \mathrm{~m}$ ), a decrease with depth in the central water layer (between about 100 and $400 \mathrm{~m}$ ) and a minimum at about $800 \mathrm{~m}$ representing the core depth of the Antarctic Intermediate Water (AAIW; Fig. 3).

At the core depth of the tropical North Atlantic OMZ; that is, at the depth of the neutral density surface $\gamma_{n}=27.1$, strongest eastward flow is found within the NICC at about $2^{\circ} \mathrm{N}$. The SICC at about $2^{\circ} \mathrm{S}$ is mostly located below this density surface. Between the surface mixed layer and $\gamma_{n}=27.1$, the main pathways along which oxygen-rich water is supplied toward the eastern Atlantic are the SEUC at about $4.5^{\circ} \mathrm{S}$ between 100 and $400 \mathrm{~m}$, the EUC at the equator between the surface and $200 \mathrm{~m}$, and the weaker eastward flow of the NECC between $4^{\circ}$ and $10^{\circ} \mathrm{N}$. The NECC has two branches. The southern branch has a narrow subsurface expression at 


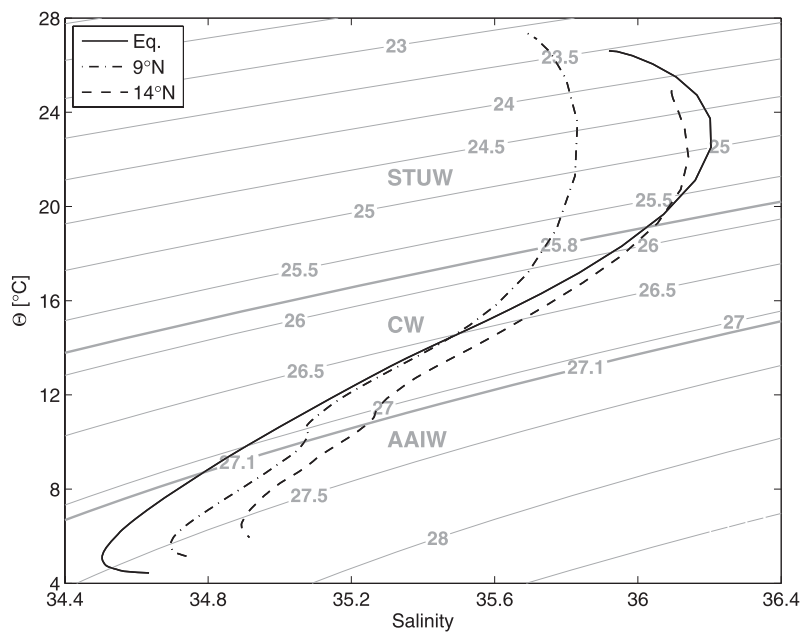

FIG. 3. Potential temperature-salinity diagram for profiles at the equator (solid), $9^{\circ} \mathrm{N}$ (dash-dotted), and $14^{\circ} \mathrm{N}$ (dashed) taken from the mean gridded fields (see Fig. 2). Gray contour lines represent $\gamma_{n}$. Thick gray lines mark the boundary between Subtropical Underwater (STUW) and central water (CW) at $\gamma_{n}=25.8$ and between CW and AAIW at $\gamma_{n}=27.1$.

about $5^{\circ} \mathrm{N}$ that represents the NEUC, which is the Northern Hemisphere counterpart to the SEUC. The northern branch of the NECC is located at about $9^{\circ} \mathrm{N}$. The eastward flow farther north, south of Cape Verde at about $13.5^{\circ} \mathrm{N}$, is most likely part of a cyclonic recirculation around the archipelago (see Mittelstaedt 1983) transporting at depths of about 100-300 m low-oxygen waters generated by enhanced biological productivity and corresponding enhanced respiration from the northeast of the islands, an area close to the coastal upwelling region off Mauritania.

A striking feature in the mean current and oxygen distributions is the strong asymmetry between the Northern and Southern Hemisphere's undercurrents (Figs. 2a,b). The NEUC is weaker and associated with an oxygen maximum mainly above the neutral density surface $\gamma_{n}=$ 26.8, while the oxygen maximum associated with the strong SEUC can be identified down to the neutral density surface $\gamma_{n}=27.1$. The larger latitudinal extent of the oxygen maximum near the NEUC compared to the one near the SEUC is probably associated with the north-south asymmetry in the appearance of tropical instability waves (Athie and Marin 2008) leading to stronger meridional eddy diffusion north than south of the equator. This asymmetry was confirmed by highresolution ocean modeling showing particularly strong meridional velocity fluctuations in the latitudinal range of the NEUC in the near-surface layer down to about $200 \mathrm{~m}$ depth (von Schuckmann et al. 2008). Northward of the NEUC down to $1000 \mathrm{~m}$ depth, direct velocity observations (Fig. 2a) suggest the existence of east- and westward current bands with amplitudes of a few centimeters per second. The observed current bands are in general agreement with float observations performed between 1994 and 2003 showing similar east- and westward current bands between 750- and 1050-m depth (Ollitrault et al. 2006). Prior to the 1990s, there are no direct velocity observations available. However, in the following we will address the question, whether part of the recently reported expansion of the North Atlantic OMZ since the 1960s (Stramma et al. 2008b) could be associated with a general weakening of the east- and westward current bands by using hydrographic data.

\section{b. Oxygen-salinity variability}

Local hydrographic distributions exhibit a large variability on small space and time scales. This variability is thought to be generated by the mesoscale eddy field and by zonal jets acting on background gradients of the different hydrographic properties. The result is the generation of fine-scale variability; that is, the formation of filaments characterized by strong lateral gradients of hydrographic properties, which ultimately must be dissipated by turbulent diffusion (Ferrari and Polzin 2005). In the following, the relationship between anomalies of oxygen $\Delta \mathrm{O}_{2}$ and salinity $\Delta S$, is analyzed (Figs. 4 and 5). These anomalies are calculated for $2^{\circ}$ latitude by $2^{\circ}$ longitude boxes by subtracting the respective box averages. To quantify the range of possible $\Delta \mathrm{O}_{2}-\Delta S$ relations, we calculated variance ellipses in the $\Delta \mathrm{O}_{2}-\Delta S$ space (encompassing $95 \%$ of the data points) that are obtained by rotating their axes into the direction of maximum variance. These ellipses are then compared with zonal and meridional $\Delta \mathrm{O}_{2}-\Delta S$ relations taken from the WGHC along the $23^{\circ} \mathrm{W}$ section from the equator to $15^{\circ} \mathrm{N}$ (dashed curves in Fig. 4) and along zonal sections from the western to the eastern boundary cutting through the box centers (solid curves in Fig. 4). The WGHC relations are derived by subtracting the WGHC oxygen and salinity values at the box centers from the WGHC oxygen and salinity values along the meridional and zonal sections, respectively. In this way, we account for different mean values of the WGHC and recent shipboard data. The intersection between the WGHC curves and the variance ellipses defines the source region of the fine-scale variability; that is, its latitudinal and longitudinal ranges. The range of the WGHC $\Delta \mathrm{O}_{2}-\Delta S$ relations covers the recent hydrographic variability except for the very low oxygen values probably originating near the eastern boundary and the very low salinity values probably originating in the Southern Hemisphere. If the WGHC curves do not intersect the variance ellipses twice, the corresponding end points of the WGHC meridional $\left(0^{\circ}\right.$ or $\left.15^{\circ} \mathrm{N}\right)$ and zonal (eastern or western boundary) 

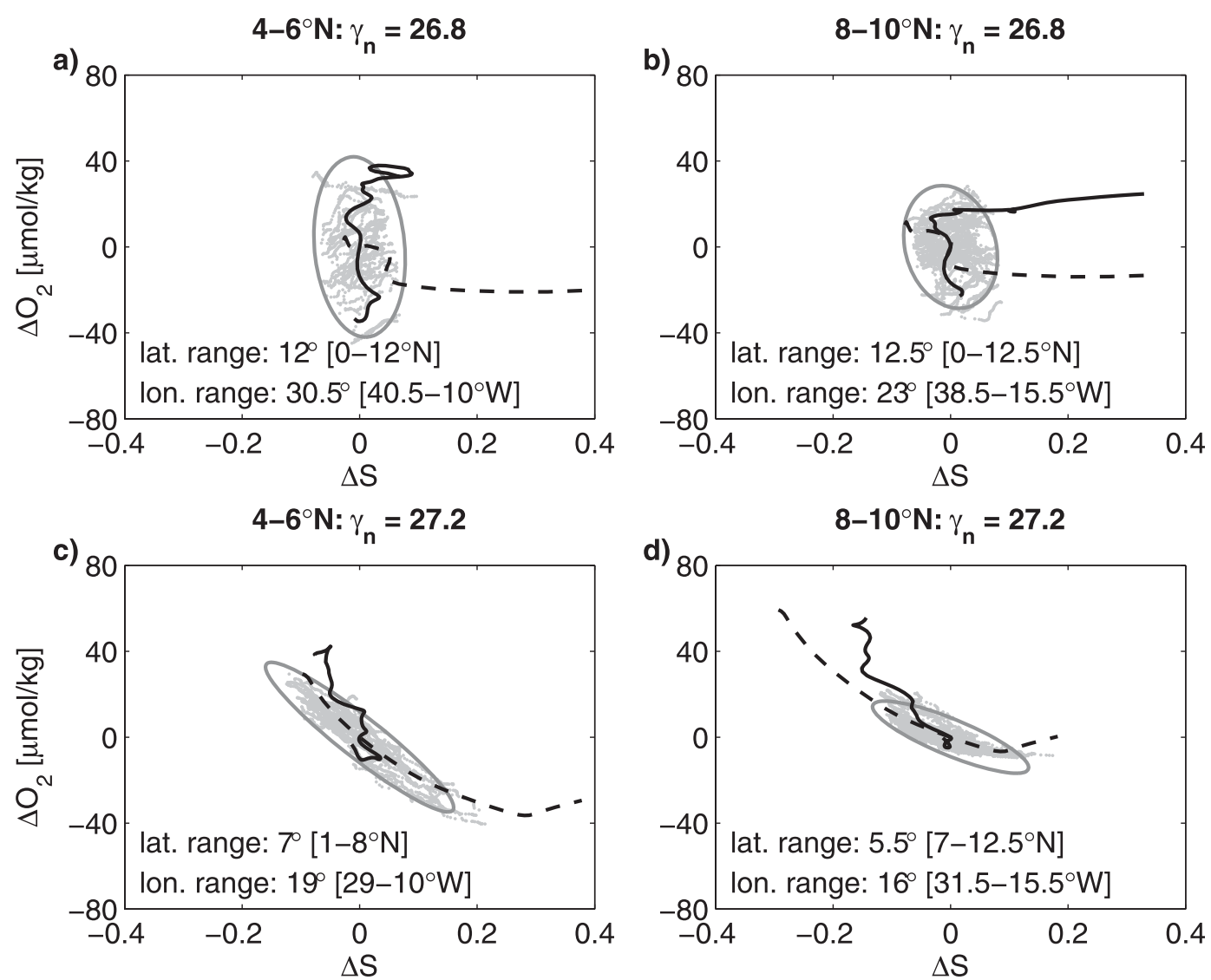

FIG. 4. The $\Delta \mathrm{O}_{2}-\Delta S$ relation between $22^{\circ}$ and $24^{\circ} \mathrm{W}$ relative to box means for the period 1999-2008 (gray dots): (a) $\gamma_{n}=26.8 \pm 0.05,4^{\circ}-6^{\circ} \mathrm{N}$; (b) $\gamma_{n}=26.8 \pm 0.05,8^{\circ}-10^{\circ} \mathrm{N}$; (c) $\gamma_{n}=27.2 \pm 0.05,4^{\circ}-6^{\circ} \mathrm{N}$; and (d) $\gamma_{n}=27.2 \pm 0.05$, $8^{\circ}-10^{\circ} \mathrm{N}$. Variance ellipses (gray solid) in the $\Delta \mathrm{O}_{2}-\Delta S$ space (encompassing $95 \%$ of the data points) are calculated by rotating their axes into the direction of maximum variance. Black dashed and black solid curves mark the WGHC $\Delta \mathrm{O}_{2}-\Delta S$ relation along meridional $\left(0^{\circ}-15^{\circ} \mathrm{N}, 23^{\circ} \mathrm{W}\right)$ and zonal $\left[(\mathrm{a}),(\mathrm{c}) 5^{\circ}\right.$ and (b), (d) $\left.9^{\circ} \mathrm{N}, 50^{\circ}-10^{\circ} \mathrm{W}\right]$ sections, respectively. Latitude and longitude ranges, with minimum and maximum in brackets, are defined by the intersection of the WGHC curves with the variance ellipses.

sections are taken as boundary of latitudinal and longitudinal ranges, respectively. Strictly speaking, these ranges can only be obtained unambiguously if the WGHC zonal and meridional $\Delta \mathrm{O}_{2}-\Delta S$ relations are linearly independent, which is only roughly the case. The obtained ranges are between $15^{\circ}$ and $25^{\circ}$ in longitude and between $5^{\circ}$ and $10^{\circ}$ in latitude indicating significantly more zonal than meridional stirring (Fig. 5).

The ratio between latitudinal and longitudinal range can be used to estimate the relative strength of zonal versus meridional stirring. According to the mixing length theory after Armi and Stommel (1983), the effective diffusivity can be estimated by $k_{e} \approx c_{e} U_{e} L_{e}$, where $c_{e}$ is an efficiency factor, $U_{e}$ is the rms eddy velocity, and $L_{e}$ is a measure of the lateral transfer scale (see Ferrari and Polzin 2005). The rms eddy velocity is proportional to the rms surface-height anomaly associated with the geostrophic eddy field $\zeta_{e}$ divided by the corresponding length scale; that is, $U_{e x} \sim \zeta_{e} / L_{e y}$ and $U_{e y} \sim \zeta_{e} / L_{e x}$. When assuming an isotropic efficiency factor (i.e., $c_{e x}=c_{e y}$ ), the resulting ratio of the effective diffusivities is

$$
\frac{k_{e x}}{k_{e y}} \sim \frac{L_{e x}^{2}}{L_{e y}^{2}} .
$$

Here we obtained a ratio of longitudinal to latitudinal range of about 3 (slightly increasing with neutral density and toward the equator) suggesting strong zonalmeridional anisotropy of the effective eddy diffusivity with the ratio of $k_{e x} / k_{e y}$ to be about 9. It is important to note that the ratio of effective diffusivities derived here also includes the stirring effect of east- and westward jets. These jets contribute to the local variability in the $\Delta \mathrm{O}_{2}-\Delta S$ relation. The anisotropy of zonal and meridional diffusivity induced by the eddy field (without the effect of zonal jets) should thus be smaller than 9 . 

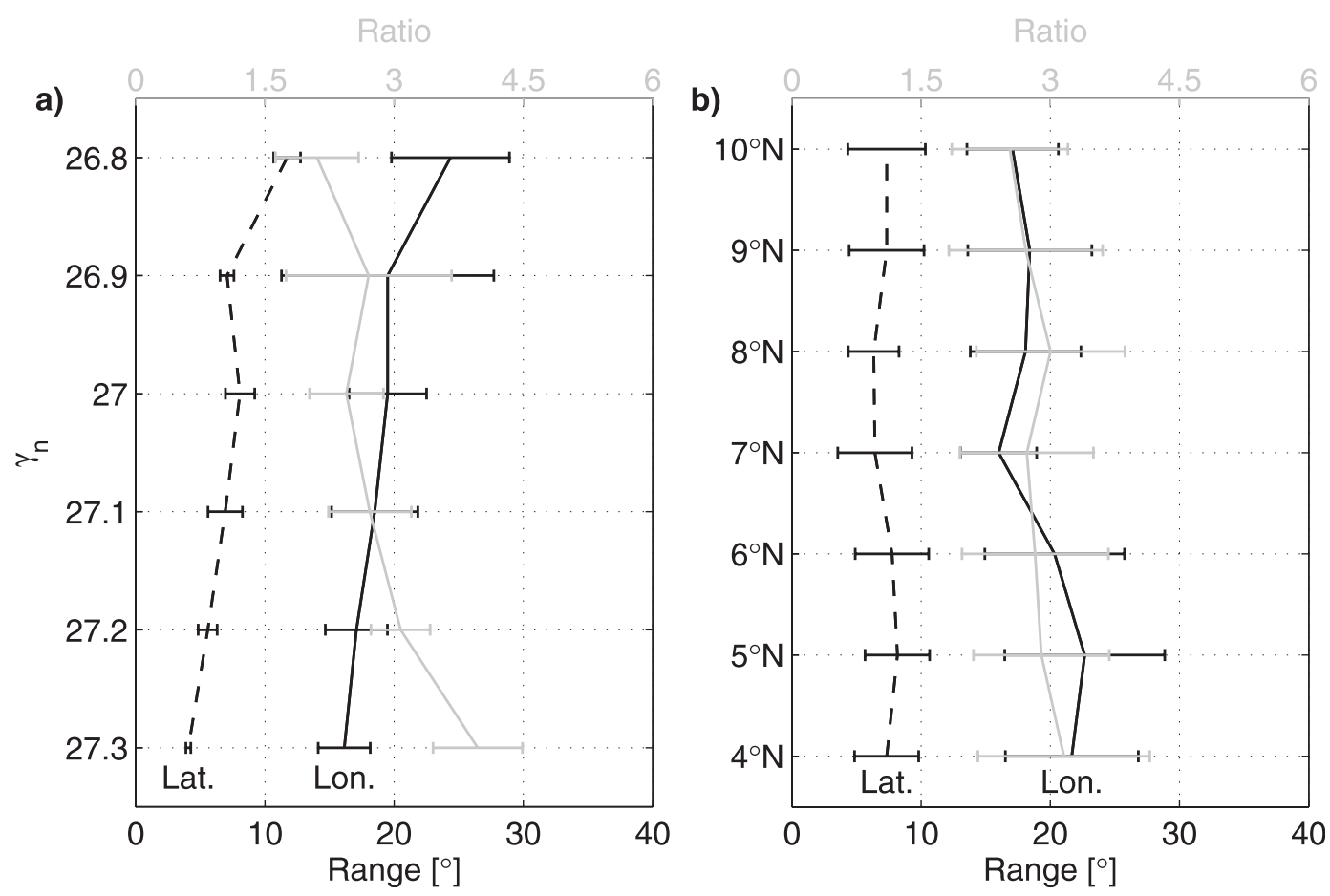

FIG. 5. Latitude and longitude ranges for the period 1999-2008 as obtained by calculating intersections of the WGHC $\Delta \mathrm{O}_{2}-\Delta S$ relations with variance ellipses in the $\Delta \mathrm{O}_{2}-\Delta S$ space (as exemplified in Fig. 4) and averaged for different $\gamma_{n}$ (a) between $4^{\circ}$ and $10^{\circ} \mathrm{N}$ as well as (b) averaged for different latitudes between $\gamma_{n}=26.8$ and 27.3. Gray curves denote the ratio between longitude and latitude range. Error bars indicate the respective standard deviation.

\section{Long-term changes}

Stramma et al. (2008b) reported an expansion of the OMZs of the tropical oceans. They particularly showed that since 1960 minimum oxygen values declined continuously and that the $\mathrm{OMZ}$ expanded vertically in the tropical North Atlantic $\left(10^{\circ}-14^{\circ} \mathrm{N}\right.$ and $\left.20^{\circ}-30^{\circ} \mathrm{W}\right)$. The downward oxygen trend of the tropical North Atlantic OMZ was estimated to be twice as large as trends obtained for the OMZs of the South Atlantic, Pacific, and Indian oceans. In comparison to the recent data presented in the previous section, we use here hydrographic data taken between $0^{\circ}$ and $14^{\circ} \mathrm{N}$ as well as $22^{\circ}$ and $24^{\circ} \mathrm{W}$ during 1972-85. This period was chosen as it is characterized by high oxygen levels and by exceptionally good data coverage.

Because no direct velocity observations are available for the period 1972-85, we calculated geostrophic zonal velocities from hydrographic data (Fig. 6a). Error estimates of geostrophic velocities referenced to $1000 \mathrm{~m}$, calculated using standard errors of the geopotential anomalies, yield an uncertainty of about $1 \mathrm{~cm} \mathrm{~s}^{-1}$ between $7^{\circ}-11^{\circ} \mathrm{N}$ and $300-500-\mathrm{m}$ depth. The geostrophic calculation results generally in an underestimation of the jet strength due to horizontal averaging and due to the chosen reference level at $1000 \mathrm{~m}$, at which zonal velocities associated with east-/westward jets could have nonzero contributions (e.g., Ollitrault et al. 2006). Data coverage does not allow deeper reference levels. Details of the geostrophic calculation and error estimates are given in the appendix.

The general structure of the zonal velocity and oxygen distributions for the period $1972-85$ is similar to those for the period $1999-2008$. The eastward jets at $6^{\circ}$ and $9^{\circ} \mathrm{N}$ are more pronounced and deeper reaching during the earlier than during the later period. The mean oxygen concentration for the period 1972-85 (Fig. 6b) is generally higher than the oxygen concentration found for the period 1999-2008 (Fig. 2b), and, associated with the stronger jets, the high-oxygen tongues near $6^{\circ}$ and $9^{\circ} \mathrm{N}$ are similarly more pronounced and deeper reaching (Fig. 6b). The comparison between the oxygen distribution in the core of the OMZ on the neutral density surface $\gamma_{n}=$ 27.1 for both periods (Fig. 7c) reveals an average reduction of the oxygen concentration by $16.6 \mu \mathrm{mol} \mathrm{kg}{ }^{-1}$ between $2^{\circ}$ and $14^{\circ} \mathrm{N}$ from the earlier to the later period, with a maximum difference of $26 \mu \mathrm{mol} \mathrm{kg}{ }^{-1}$ at $3^{\circ} \mathrm{N}$. Near the equator, however, the changes are weak. At the same time, the mean depth of the neutral density surface $\gamma_{n}=$ 27.1 stays almost constant, with stronger undulations 

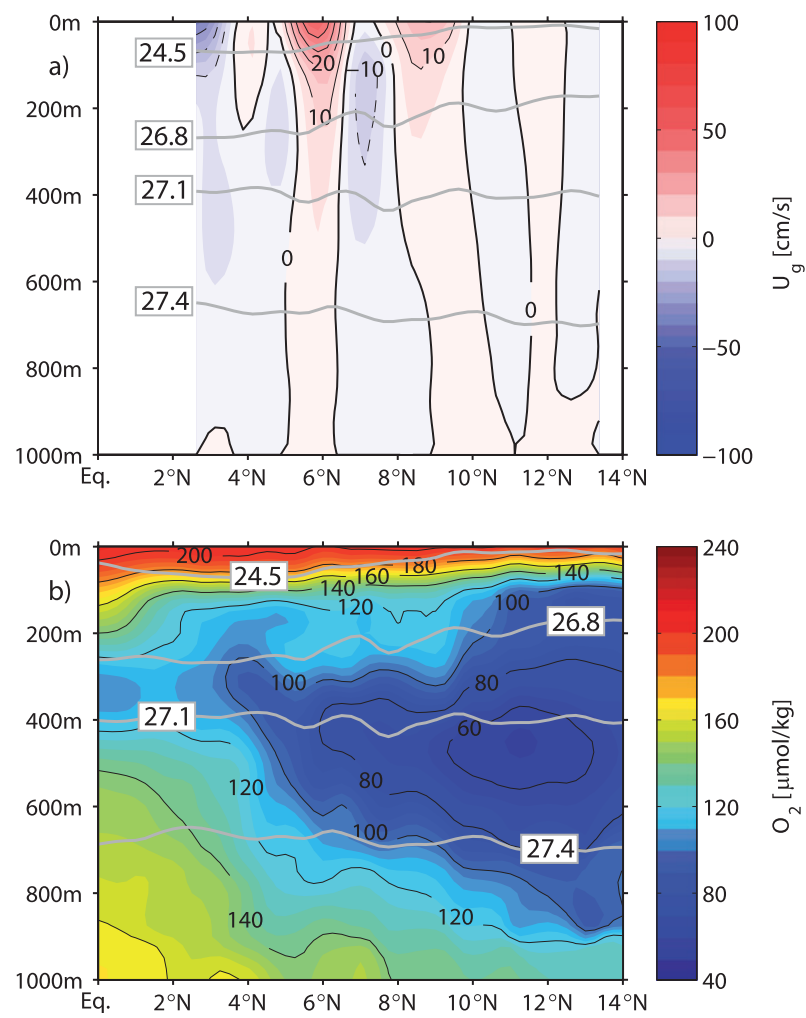

FIG. 6. (a) Mean geostrophic zonal velocity and (b) oxygen content along $\sim 23^{\circ} \mathrm{W}$ from hydrographic measurements taken during 1972-85. Gray lines mark $\gamma_{n}$. The mean oxygen distribution is derived by first binning the data on regular $0.25^{\circ}$ latitude $\times 25-\mathrm{m}$ depth grids; that is, we calculated half-overlapping box averages of width $0.5^{\circ}$ and height $50 \mathrm{~m}$. Finally, the data are smoothed by a Gaussian interpolation scheme [horizontal and vertical influence (cutoff) radii: $0.5^{\circ}\left(1^{\circ}\right)$ and $50 \mathrm{~m}(100 \mathrm{~m})$, respectively].

during the earlier compared to the later period (Fig. 7d). Accordingly, zonal jets on the neutral density surface $\gamma_{n}=27.1$ show substantially stronger amplitudes in the region between $4^{\circ}$ and $10^{\circ} \mathrm{N}$ (Fig. 7a) and are associated with stronger oxygen undulations, particularly visible when subtracting the background oxygen curvature (Fig. 8).

Between the equator and the Cape Verde frontal zone at $15^{\circ}$ to $20^{\circ} \mathrm{N}$, water masses of Southern and Northern Hemisphere origin form an extended transition zone that is reflected in an almost linear salinity increase from south to north on neutral density surfaces near the core of the OMZ (Fig. 7b). To avoid biases by local variations in the partitioning of waters of Southern and Northern Hemisphere origin, apparent oxygen utilization (AOU, defined as the air saturation value of dissolved oxygen at a given temperature and salinity minus the measured dissolved oxygen) is now used instead of dissolved oxygen itself. Here AOU is analyzed as a function of salinity for the two periods $1972-85$ and $1999-2008$ on the neutral density surface $\gamma_{n}=27.1$ (Fig. 9). In the core of
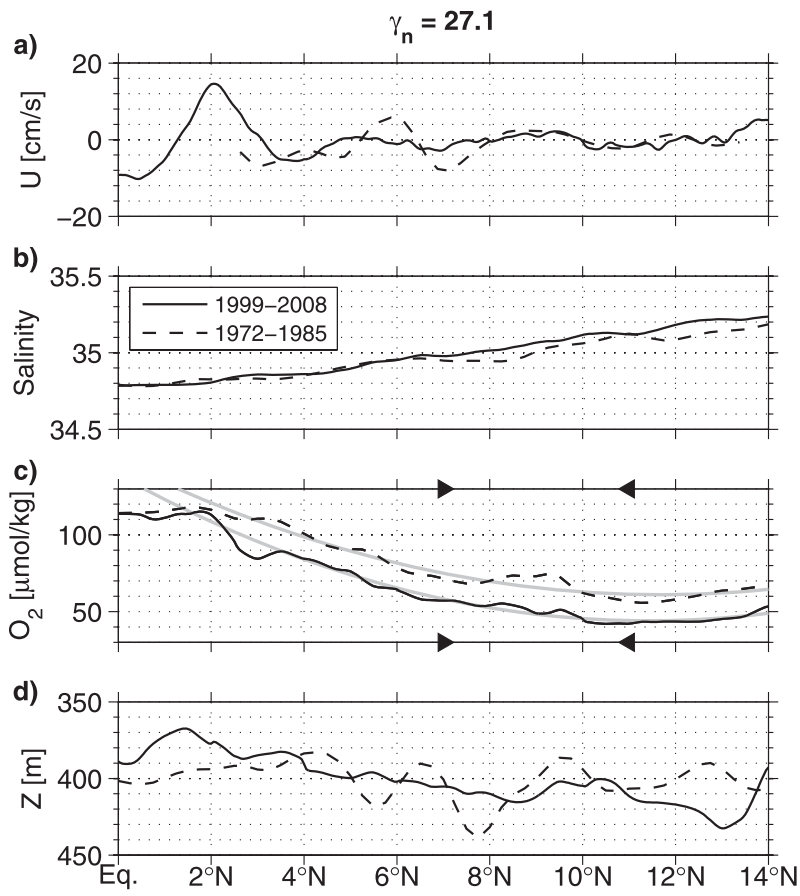

FIG. 7. (a) Mean zonal velocity, (b) salinity, (c) oxygen, and (d) depth on $\gamma_{n}=27.1$ along $\sim 23^{\circ} \mathrm{W}$ as function of latitude for the periods 1999-2008 (black solid) and 1972-85 (black dashed). In (a), the zonal velocity for the later period is obtained from direct velocity measurements and for the earlier period from geostrophic calculations using a reference level of $1000 \mathrm{~m}$. (c) The latitudinal model extent is indicated by the triangles and the second-order fits to the large-scale meridional oxygen field between $4^{\circ}$ and $14^{\circ} \mathrm{N}$ are also shown (gray solid): $D_{y}(1999-2008)=1.2 \times 10^{-10} \mu \mathrm{mol} \mathrm{kg}^{-1} \mathrm{~m}^{-2}$ and $D_{y}(1972-85)=1.0 \times 10^{-10} \mu \mathrm{mol} \mathrm{kg}{ }^{-1} \mathrm{~m}^{-2}$.

the OMZ, a significant mean oxygen decrease (or AOU increase) between the two periods of $14.7 \mu \mathrm{mol} \mathrm{kg}^{-1}$ is found for salinities larger than 35 . Over the same time interval, the salinity at the oxygen minimum (or AOU maximum) increased by about 0.1 indicating a relatively stronger contribution of Northern Hemisphere waters.

For the time periods $1972-85$ and 1999-2008, the salinity and AOU data are mapped onto regular $1^{\circ}$ latitude $\times 0.1$ neutral density grids. To reduce further the noise inherent in the data, we actually averaged over $1.5^{\circ}$ wide intervals in latitude (i.e., $\pm 0.75^{\circ}$ of the nominal latitude), before we calculated the differences between the two periods (Fig. 10). Along the $23^{\circ} \mathrm{W}$ section, salinity changes from 1972-85 to 1999-2008 vary for different neutral density surfaces. While we observe an increase in salinity in the core layer of the $\mathrm{OMZ}$ north of $6^{\circ} \mathrm{N}$, the salinity changes only weakly or even decreases above the OMZ core (Fig. 10a). A simultaneous increase of AOU is evident in the core layer of the OMZ across the whole tropical North Atlantic between the equator and $14^{\circ} \mathrm{N}$, as well as above the $\mathrm{OMZ}$ core south of $10^{\circ} \mathrm{N}$ 

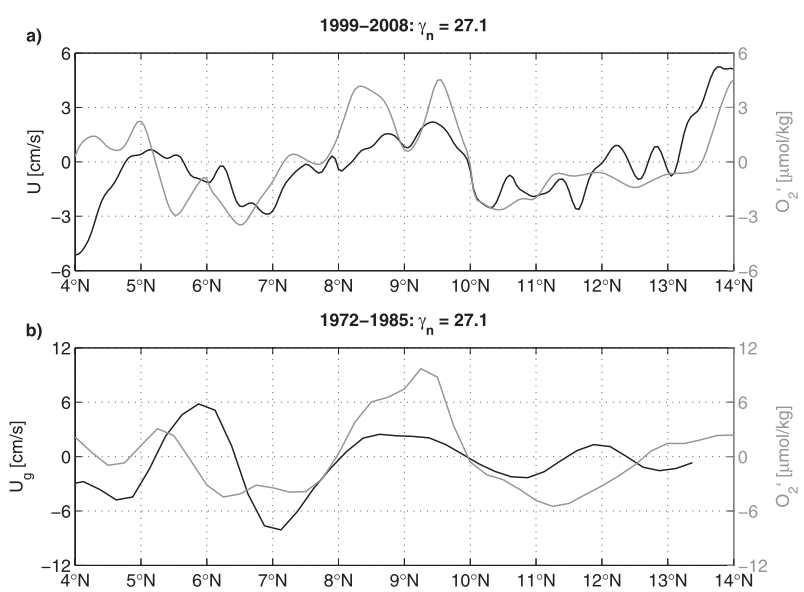

FIG. 8. Mean zonal velocity (black) and oxygen anomaly (gray) on $\gamma_{n}=27.1$ along $\sim 23^{\circ} \mathrm{W}$ as function of latitude for the periods (a) 1999-2008 and (b) 1972-85. The zonal velocity for the latter period is obtained from direct velocity measurements and for the earlier period from geostrophic calculations using a reference level of $1000 \mathrm{~m}$. The oxygen anomalies for both periods are calculated by subtracting the second order fits depicted in Fig. 7c. Note that the $y$ axis ranges are doubled in (b) compared to (a).

(Fig. 10b). In particular within the latitudinal range of the eastward flowing current band at around $9^{\circ} \mathrm{N}$ (see Fig. 2a), the salinity decreases in the neutral density layers $\gamma_{n}=26.6-26.8$, while it increases in deeper layers (Fig. 10a). As the boundary between North and South Atlantic water masses is directed from southwest to northeast in the central water layer but from northwest to southeast in the AAIW layer (Kirchner et al. 2009), zonally inflowing oxygen-rich water masses may transport positive (negative) salinity anomalies above (below) $\gamma_{n}=26.9$ into the OMZ, respectively.

Another possibility to explain the observed changes on neutral density surfaces would be a change of source water properties. In fact, calculations of salinity trends from hydrographic data for the period from the 1960s to 1990s revealed a general increase in salinity in the central water masses of subtropical origin and a decrease in salinity in intermediate water masses of subpolar origin, suggesting a change in the freshwater balance of the global oceans (Curry et al. 2003; Boyer et al. 2005). These changes, estimated for a period shifted backward in time by about 10 years, are of reversed sign than observed here. Moreover, changes in salinity of about 0.1 on the neutral density surface $\gamma_{n}=27.1$ (Fig. 9) are an order of magnitude larger than those reported by Curry et al. (2003) and are not likely produced by changes of the properties of the source waters.

The $\Delta \mathrm{O}_{2}-\Delta S$ relations for the period 1972-85 reveal an elevated scatter compared to the period 1999-2008 that is well above the estimated accuracy of the historical
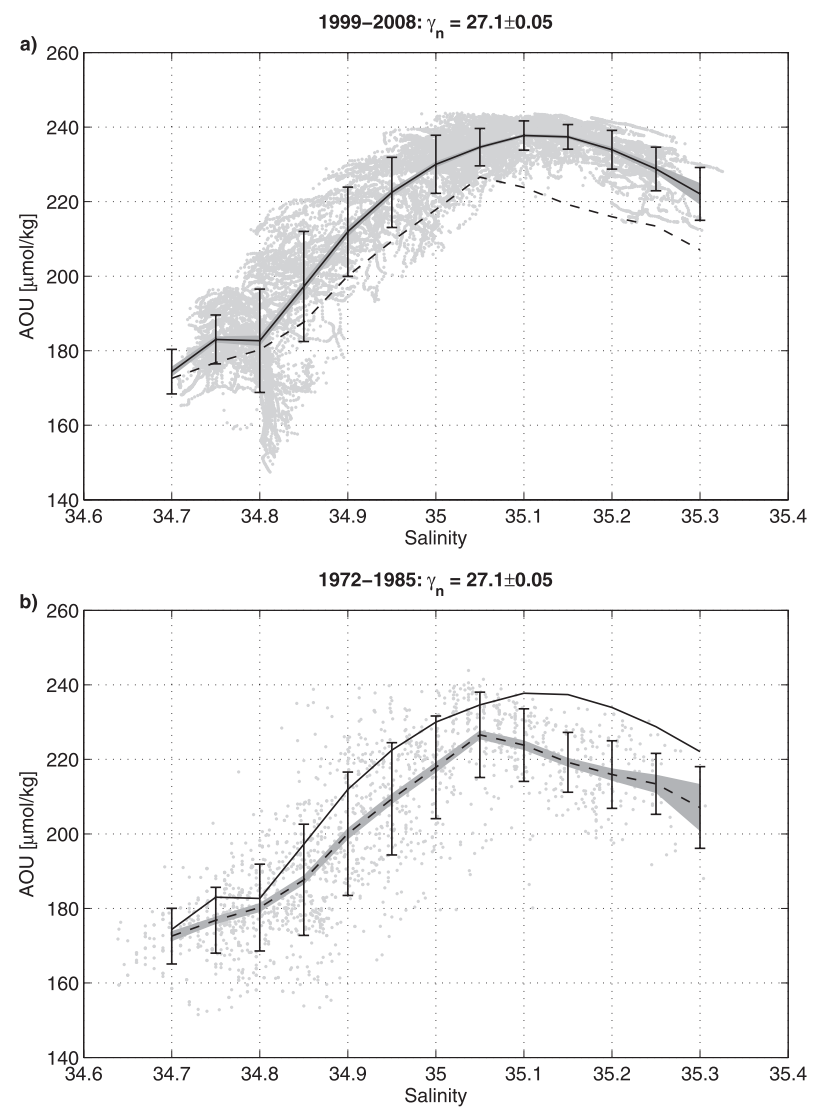

FIG. 9. AOU on $\gamma_{n}=27.1 \pm 0.05$ as function of salinity for the two periods (a) 1999-2008 and (b) 1972-85 (gray dots). Mean curves are derived for salinity bins of 0.05 for the two periods 1999 2008 (solid) and 1972-85 (dashed), with standard deviations (bars) and standard errors (gray shaded). Data points were measured within the region $0^{\circ}-14^{\circ} \mathrm{N}, 22^{\circ}-24^{\circ} \mathrm{W}$. Standard error of the mean AOU within each salinity bin is calculated by assuming that different hydrographic profiles represent independent data.

data (cf. Figs. 4 and 11). The resulting latitudinal and longitudinal ranges exceed on average the ranges for the later period by a factor of 1.3 , even though very similar values are obtained at $10^{\circ} \mathrm{N}$ (Fig. 12). However, the ratio between latitudinal and longitudinal range remains almost constant. The elevated scatter in the $\Delta \mathrm{O}_{2}-\Delta S$ relations during 1972-85 additionally suggests enhanced ventilation during the earlier period.

\section{Conceptual model of the OMZ}

A conceptual model of the ventilation of the $\mathrm{OMZ}$ is used here to corroborate the hypothesis that alternating zonal jets contribute to the ventilation of the OMZ and that reasonable variations of their strength may result in changes of the mean oxygen levels in the OMZ, comparable in magnitude to observed long-term changes. The model is representative only for a single eastward 

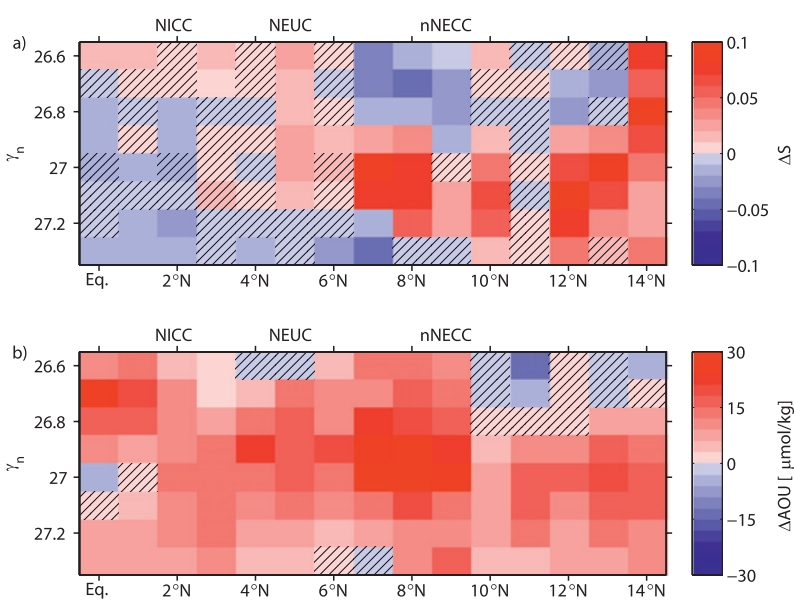

FIG. 10. Differences in (a) salinity and (b) AOU between the periods 1999-2008 and 1972-85 as function of $\gamma_{n}$ and latitude (see text for details). Absolute differences in salinity and AOU that are smaller than their standard error are hatched.

jet and its westward return flow, superimposed on the background meridional curvature of the oxygen distribution. It simulates the oxygen supply by mean zonal and meridional advection associated with the jet, by zonal and meridional eddy diffusivity, and by vertical (diapycnal) eddy diffusivity. The model is aimed at calculating the oxygen balance in an OMZ composed of multiple alternating zonal jets on a given density surface. We will show that reasonable jet strengths yield an advective oxygen supply that is comparable in magnitude to the diffusive supply. We chose parameters that correspond to the core of the North Atlantic OMZ; that is, the neutral density surface $\gamma_{n}=27.1$. With this conceptual model, we want to address the question: What are the necessary changes in the strength of zonal jets or lateral eddy diffusivity that would yield similar changes in the oxygen concentration as observed between the two periods $1972-85$ and $1999-2008$.

\section{a. Model}

The conceptual model is an advection-diffusion model that will be integrated until equilibrium is reached:

$$
\begin{aligned}
\frac{\partial C}{\partial t}= & -J C-u \frac{\partial C}{\partial x}-v \frac{\partial C}{\partial y}+k_{x} \frac{\partial^{2} C}{\partial x^{2}}+k_{y} \frac{\partial^{2} C}{\partial y^{2}} \\
& +k_{y} F_{\text {corr }} \frac{\partial^{2} C_{\mathrm{bg}}}{\partial y^{2}}+k_{z} F_{\text {corr }} \frac{\partial^{2} C_{\mathrm{bg}}}{\partial z^{2}} .
\end{aligned}
$$

Here $C$ is the dissolved oxygen concentration; $J$ the constant dissolved oxygen consumption coefficient; $u$ and $v$ the zonal and meridional velocity components, respectively; $k_{x}$ and $k_{y}$ the coefficients of the zonal and meridional eddy diffusivities, respectively; $k_{z}$ the coefficient of the vertical eddy diffusivity; $C_{\mathrm{bg}}$ the constant large-scale background oxygen distribution; and $F_{\text {corr }}$ a correction factor to the background oxygen curvature depending on the simulated oxygen concentration. In the model [Eq. (2)], the oxygen tendency on the left-hand side is attributed to the following seven terms on the right-hand side: 1) oxygen consumption, 2) zonal advection, 3) meridional advection, 4) zonal eddy diffusivity, 5) meridional eddy diffusivity associated with east- and westward jets, 6) meridional eddy diffusivity associated with the large-scale oxygen distribution between the equatorial region and the northern subtropics, and 7) vertical eddy diffusivity associated with the vertical oxygen distribution. The dissolved oxygen consumption constant is taken from van Geen et al. (2006), who obtained an estimate by constraining a one-dimensional advection-diffusion model for the North Pacific OMZ with chlorofluorocarbon data. Their best-fit value was $J=0.041 \mathrm{yr}^{-1}$. The model will be solved numerically for a region covering simplified east- and westward zonal flows between $7^{\circ} \mathrm{N}(y=0)$ and $11^{\circ} \mathrm{N}\left(y=l_{y}\right)$ and between the western boundary regime at $50^{\circ} \mathrm{W}(x=0)$ and the eastern boundary at $15^{\circ} \mathrm{W}\left(x=l_{x}\right)$. We assume the following prescribed background flow field:

$$
u=u_{0} \frac{l_{x}-x}{l_{x}} \cos \left(\frac{2 \pi y}{l_{y}}\right), \quad v=-\frac{u_{0}}{2 \pi} \frac{l_{y}}{l_{x}} \sin \left[\frac{2 \pi y}{l_{y}}\right],
$$

where $u_{0}$ is the amplitude of the zonal jets at the western boundary. The zonal flow decreases linearly toward the east. The meridional velocity field is calculated using the continuity equation. The meridional eddy diffusivity associated with the large-scale oxygen distribution is approximated using a second-order fit to the observed oxygen distribution along $23^{\circ} \mathrm{W}$ between $4^{\circ}$ and $14^{\circ} \mathrm{N}$ (see Fig. 7c). We obtained very similar values for the distributions of the two time periods as well as for the WGHC distribution. In the model we use $\partial^{2} C_{\mathrm{bg}} / \partial y^{2}=$ $D_{y}=1.2 \times 10^{-10} \mu \mathrm{mol} \mathrm{kg}{ }^{-1} \mathrm{~m}^{-2}$. The vertical eddy diffusivity associated with the vertical curvature of the oxygen distribution is similarly obtained using secondorder fits. These fits are applied to the observed oxygen distribution between 300 and $500 \mathrm{~m}$ at each latitudinal grid point between $7^{\circ}$ and $11^{\circ} \mathrm{N}$. The obtained mean second order fits are $\partial^{2} C_{\mathrm{bg}} / \partial z^{2}=D_{z}=1.5 \times$ $10^{-3} \mu \mathrm{mol} \mathrm{kg} \mathrm{km}^{-1}$ for the period $1972-85$ and $D_{z}=$ $1.7 \times 10^{-3} \mu \mathrm{mol} \mathrm{kg}{ }^{-1} \mathrm{~m}^{-2}$ for the period 1999-2008. In the following, we will use the latter value for the more recent period. We assume that both terms associated with the background oxygen distribution are constant for the whole model domain. Additionally, we apply the following boundary conditions: 

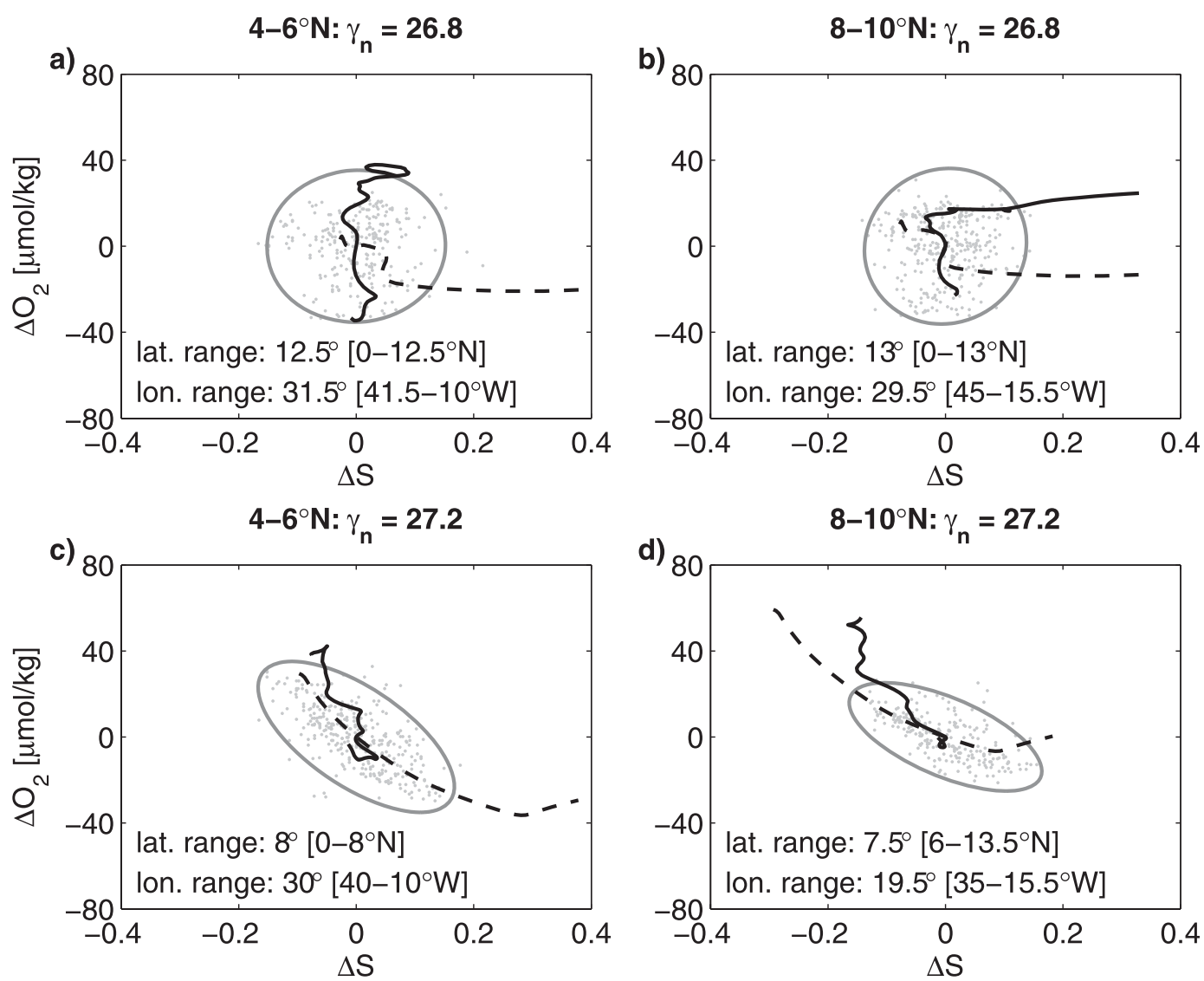

FIG. 11. As in Fig. 4, but for the period 1972-85.

$$
\begin{gathered}
C=C_{0} \quad \text { at } \quad x=0, \quad \frac{\partial C}{\partial x}=0 \quad \text { at } \quad x=x_{l}, \quad \text { and } \\
\frac{\partial C}{\partial y}=0 \quad \text { at } \quad y=0 \text { and } y=y_{l} .
\end{gathered}
$$

The dissolved oxygen concentration at the western boundary $C_{0}$ is chosen to be $120 \mu \mathrm{mol} \mathrm{kg}{ }^{-1}$. The correction factor for the background meridional diffusivity is defined as follows:

$$
F_{\text {corr }}=\frac{C_{0}-\overline{C_{23 \mathrm{~W}}}}{C_{0}-C_{1}}
$$

Here $C_{1}$ is the observed mean oxygen concentration along $23^{\circ} \mathrm{W}$ between $7^{\circ}$ and $11^{\circ} \mathrm{N}$; that is, $50 \mu \mathrm{mol} \mathrm{kg}{ }^{-1}$, and $\overline{C_{23 \mathrm{~W}}}$ is the corresponding simulated value. If $\overline{C_{23 \mathrm{~W}}}$ becomes close to $C_{0}$ the factor tends to 0 ; that is, no meridional background eddy diffusivity; if $\overline{C_{23 \mathrm{~W}}}$ is equal to $C_{1}$ the factor is 1 . This correction factor acts to increase/decrease the oxygen supply because of the background eddy diffusivity for reduced/increased oxygen concentration in the OMZ. For the range of observed oxygen concentrations, this factor only slightly changes the obtained solution (resulting in a slight damping of oxygen changes). This correction factor is also applied to the vertical diffusion as the vertical oxygen curvature should similarly decrease/increase for periods with enhanced/reduced oxygen levels in the core of the OMZ.

The diffusive solution of Eq. (2) with $u_{0}=0 \mathrm{~cm} \mathrm{~s}^{-1}$ can be obtained for $F_{\text {corr }}=1$ :

$$
C=\frac{k_{y} D_{y}+k_{z} D_{z}}{J}+\left(C_{0}-\frac{k_{y} D_{y}+k_{z} D_{z}}{J}\right) \exp \left(-\sqrt{\frac{J}{k_{x}}} x\right) .
$$

This solution yields with the above assumptions for $J$, $D_{y}$, and $D_{z}$, with $k_{y}=200 \mathrm{~m}^{2} \mathrm{~s}^{-1}$, vanishing zonal eddy diffusivity at the eastern boundary, and $k_{z}=10^{-5} \mathrm{~m}^{2} \mathrm{~s}^{-1}$ (Ledwell et al. 1993), a minimum oxygen concentration at the eastern boundary of $32 \mu \mathrm{mol} \mathrm{kg}{ }^{-1}$.

\section{b. Results}

Using the above definitions, we will analyze the model behavior to variations of its free parameters amplitude of zonal jets and zonal and meridional diffusion coefficients. Our measurements of the zonal velocity along 

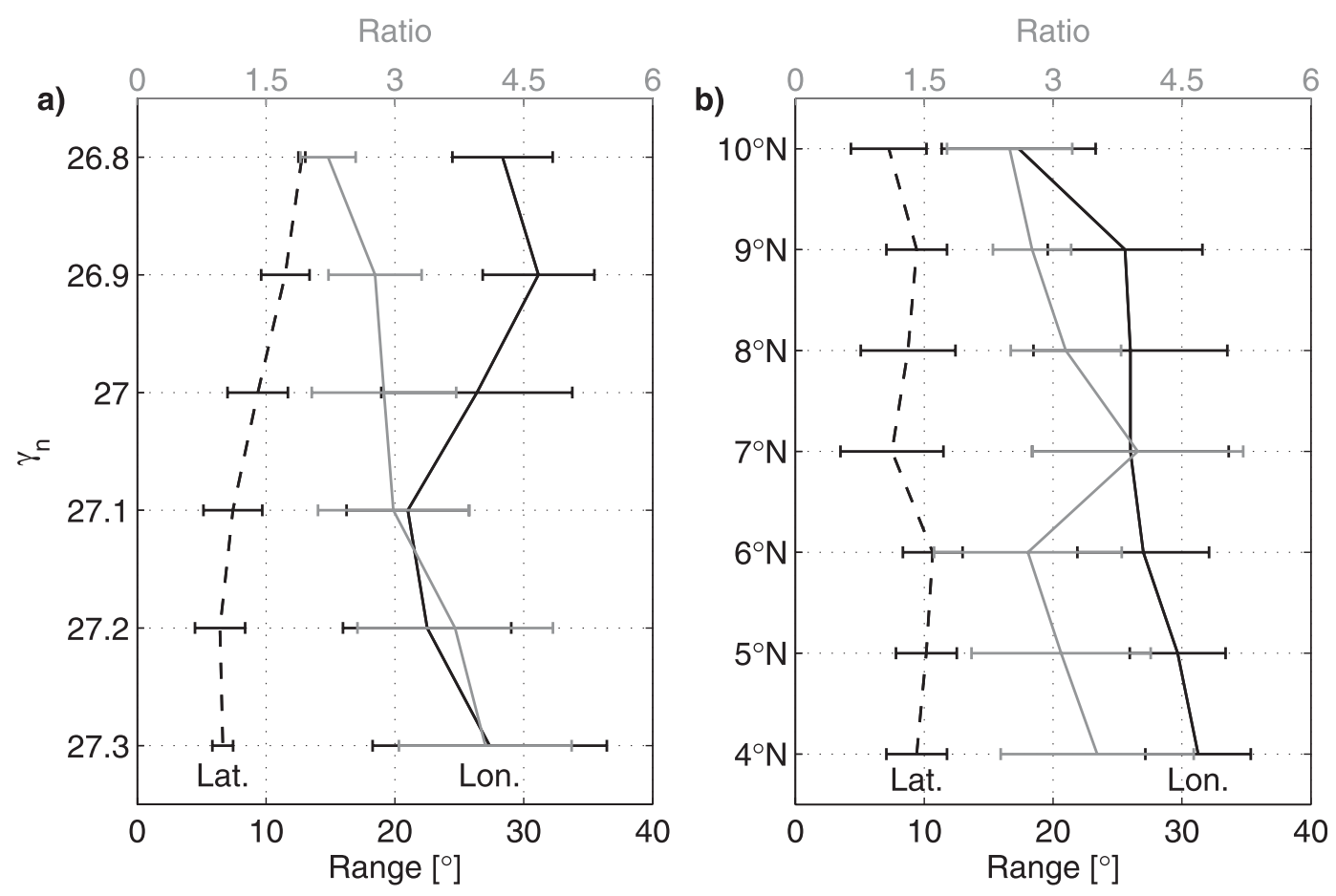

FIG. 12. As in Fig. 5, but for the period 1972-85.

$23^{\circ} \mathrm{W}$ suggest that the amplitude of the jets within the OMZ is of the order of a few centimeters per second (Fig. 8). This is generally confirmed by high-resolution model results (Nakano and Hasumi 2005; Richards et al. 2006; Eden 2006). Estimates of lateral eddy diffusivities were obtained for the eastern subtropical North Atlantic where an intense field program associated with the North Atlantic Tracer Release Experiment (Ledwell et al. 1998) and the Subduction Experiment (Joyce et al. 1998) was carried out in 1991-93. Eddy diffusivity coefficients of about $1000 \mathrm{~m}^{2} \mathrm{~s}^{-1}$ were found in the upper $400 \mathrm{~m}$ of the water column that drop to $350-500 \mathrm{~m}^{2} \mathrm{~s}^{-1}$ at about $1000 \mathrm{~m}$ without zonal-meridional anisotropy (Ferrari and Polzin 2005). In the OMZ south of the Cape Verde archipelago, the eddy diffusivities should be substantially smaller as suggested by high-resolution numerical simulations that additionally revealed pronounced zonalmeridional anisotropy (Eden et al. 2007; Eden and Greatbatch 2008).

In the following, we will discuss three simulations with the model, SIM 1-3 [Eq. (2)]. Using $u_{0}=5 \mathrm{~cm} \mathrm{~s}^{-1}, k_{x}=$ $500 \mathrm{~m}^{2} \mathrm{~s}^{-1}$, and $k_{y}=200 \mathrm{~m}^{2} \mathrm{~s}^{-1}$; that is, an anisotropy of $2.5^{2}$ (SIM 1 ), we derive an oxygen distribution that is

\footnotetext{
${ }^{2}$ The chosen lateral diffusivity coefficients are educated guesses that are roughly consistent with realistic high-resolution models as the one used by Eden et al. (2007) as well as Eden and Greatbatch (2008).
}

characterized by an oxygen tongue centered at the position of the eastward jet at $9^{\circ} \mathrm{N}$ superimposed on an overall eastward decrease of the oxygen concentration (Fig. 13a). This simulation is compared to a simulation with reduced strength of the zonal jets; that is, $u_{0}=$ $2.5 \mathrm{~cm} \mathrm{~s}^{-1}$ (SIM 2), and with the purely diffusive solution, $u_{0}=0 \mathrm{~cm} \mathrm{~s}^{-1}$ (SIM 3). The existence of zonal jets leads to higher oxygen concentrations in the OMZ. This effect diminishes with decreasing strength of the jets (Fig. 13b). The amplitude of the oxygen undulations along $23^{\circ} \mathrm{W}$ associated with east- and westward jets also reduces with decreasing strength of the jets (Fig. 13c).

The oxygen concentration obtained for $u_{0}=0 \mathrm{~cm} \mathrm{~s}^{-1}$ is clearly below the recently observed oxygen concentration in the OMZ of the tropical North Atlantic; that is, there must be additional ventilation due to zonal advection. On the other hand, this value is clearly above suboxic conditions $\left(C<10 \mu \mathrm{mol} \mathrm{kg}^{-1}\right)$. Compared to the Pacific OMZs, the much higher oxygen concentration in the tropical North Atlantic OMZ is very likely achieved by the meridional eddy diffusivity associated with the large-scale oxygen distribution [term 6 on the right-hand side of Eq. (2)]. In particular, the high oxygen concentration in the equatorial region is responsible for the present day meridional curvature of the large-scale oxygen distribution $D_{y}$. Without changing the meridional curvature, a switch of the tropical North Atlantic OMZ into suboxic conditions could, even with vanishing 

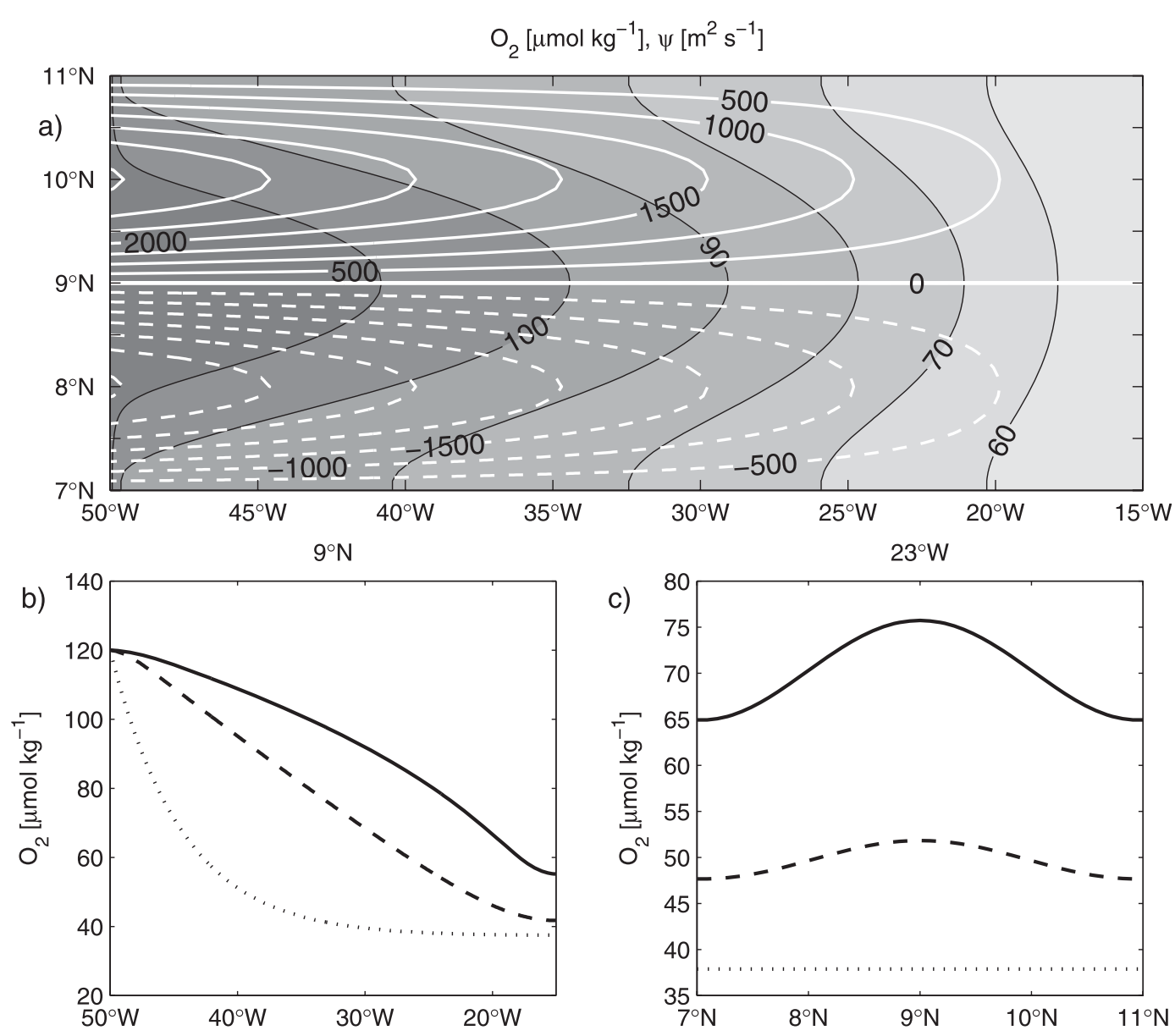

FIG. 13. (a) Oxygen distribution (black lines, gray shading, $120 \mu \mathrm{mol} \mathrm{kg}{ }^{-1}$ at $50^{\circ} \mathrm{W}, 10 \mu \mathrm{mol} \mathrm{kg}^{-1}$ intervals) and streamfunction (white lines, solid = positive, dashed = negative, $500 \mathrm{~m}^{2} \mathrm{~s}^{-1}$ intervals) as simulated using Eq. (2) with $u_{0}=5 \mathrm{~cm} \mathrm{~s}^{-1}, k_{x}=500 \mathrm{~m}^{2} \mathrm{~s}^{-1}$, and $k_{y}=200 \mathrm{~m}^{2} \mathrm{~s}^{-1}$. (b) Zonal and (c) meridional oxygen distribution along $9^{\circ} \mathrm{N}$ and $23^{\circ} \mathrm{W}$, respectively; solid, dashed, and dotted curves are model solutions for $u_{0}=5 \mathrm{~cm} \mathrm{~s}^{-1}$ (SIM 1$), u_{0}=2.5 \mathrm{~cm} \mathrm{~s}^{-1}$ (SIM 2), and $u_{0}=0 \mathrm{~cm} \mathrm{~s}^{-1}$ (SIM 3), respectively.

oxygen supply by zonal jets, only be achieved by a substantial increase of the oxygen consumption coefficient by a factor of 2-3.

The magnitude of the different terms in Eq. (2), averaged over the box $7^{\circ}-11^{\circ} \mathrm{N}$ and $22^{\circ}-24^{\circ} \mathrm{W}$, is summarized in Table 3. The oxygen consumption (term 1) decreases with decreasing oxygen concentration and the supply by the meridional and vertical eddy diffusivities associated with the background oxygen distribution (terms 6 and 7) increases with decreasing oxygen concentration. The magnitudes of the latter two terms are of the same order, with meridional eddy diffusivity being only slightly larger than vertical eddy diffusivity. The effect of the zonal eddy diffusivity (term 4) is small compared to the oxygen consumption and can even change its sign locally. Across the whole box, the meridional eddy diffusivity associated with the jets (term 5) redistributes oxygen between east- and westward jets without a net effect on the oxygen balance of the OMZ. Zonal and meridional advection (term 2 and 3, respectively) are of similar magnitude, but smaller than the oxygen consumption. In general, the relative importance of meridional and vertical eddy diffusivity associated with the background oxygen distribution for the ventilation of the OMZ increases with decreasing strength of the zonal jets. The model results suggest that a reduction of the amplitude of the zonal jets leads to a reduction of (i) the oxygen concentration in the OMZ, and (ii) the amplitudes of oxygen undulations along the $23^{\circ} \mathrm{W}$ section.

The dependence of the absolute oxygen minimum of the OMZ on the two parameters $u_{0}$ and $k_{y}$ as obtained by the model is plotted in Fig. 14. Here we apply three different degrees of anisotropy between zonal and meridional diffusivities: $1,2.5$, and 10 . However, because of the small net effect of the zonal eddy diffusivity on the oxygen balance in the OMZ, the absolute oxygen 
TABLE 3. Parameters used for the three simulations (SIM 1, SIM 2, SIM 3) as well as the magnitude of the terms on the rhs of Eq. (2) and simulated mean oxygen concentration. The different terms as well as the oxygen concentration are averaged between $7^{\circ}$ and $11^{\circ} \mathrm{N}$ and between $22^{\circ}$ and $24^{\circ} \mathrm{W}$.

\begin{tabular}{lccc}
\hline \multicolumn{1}{c}{ Parameter/term } & SIM 1 & SIM 2 & SIM 3 \\
\hline$u_{0}\left(\mathrm{~cm} \mathrm{~s}^{-1}\right)$ & 5 & 2.5 & 0 \\
$k_{y}\left(\mathrm{~m}^{2} \mathrm{~s}^{-1}\right)$ & 200 & 200 & 200 \\
$k_{x}\left(\mathrm{~m}^{2} \mathrm{~s}^{-1}\right)$ & 500 & 500 & 500 \\
$-J C\left(\mu \mathrm{mol} \mathrm{kg}^{-1} \mathrm{yr}^{-1}\right)$ & -2.88 & -2.04 & -1.55 \\
$-u \partial C / \partial x\left(\mu \mathrm{mol} \mathrm{kg}^{-1} \mathrm{yr}^{-1}\right)$ & 0.94 & 0.37 & 0 \\
$-v \partial C / \partial y\left(\mu \mathrm{mol} \mathrm{kg}^{-1} \mathrm{yr}^{-1}\right)$ & 1.14 & 0.22 & 0 \\
$k_{x} \partial^{2} C / \partial x^{2}\left(\mu \mathrm{mol} \mathrm{kg}^{-1} \mathrm{yr}^{-1}\right)$ & -0.12 & 0.14 & 0.03 \\
$k_{y} \partial^{2} C / \partial y^{2}\left(\mu \mathrm{mol} \mathrm{kg}^{-1} \mathrm{yr}^{-1}\right)$ & 0 & 0 & 0 \\
$k_{y} F_{\text {corr }} \partial^{2} C_{\mathrm{bg}} / \partial y^{2}\left(\mu \mathrm{mol} \mathrm{kg}^{-1} \mathrm{yr}^{-1}\right)$ & 0.54 & 0.76 & 0.89 \\
$k_{z} F_{\text {corr }} \partial^{2} C_{\mathrm{bg}} / \partial z^{2}\left(\mu \mathrm{mol} \mathrm{kg}^{-1} \mathrm{yr}^{-1}\right)$ & 0.38 & 0.54 & 0.63 \\
$C_{23 \mathrm{~W}}\left(\mu \mathrm{mol} \mathrm{kg} \mathrm{mg}^{-1}\right)$ & 70.3 & 49.7 & 37.9 \\
\hline
\end{tabular}

minimum mainly depends on $u_{0}$ and $k_{y}$, the degree of anisotropy plays only a minor role. These simulations suggest that a reduction of the meridional eddy diffusivity coefficient from about 500 to $250 \mathrm{~m}^{2} \mathrm{~s}^{-1}$ with $u_{0}=$ $0 \mathrm{~cm} \mathrm{~s}^{-1}$ and anisotropy of 2.5 yields similar changes in the $\mathrm{OMZ}$ as the reduction in strength of the zonal jets discussed before. However, simulations with very small $u_{0}$ show strongly reduced amplitudes of the oxygen undulations along the $23^{\circ} \mathrm{W}$ section and are thus not able to reproduce observed undulations (Fig. 13c).

\section{Summary and discussion}

A large number of recent research cruise data (Table 1) allows a detailed description of the mean circulation and hydrographic properties as well as their variability along the $23^{\circ} \mathrm{W}$ meridian from $6^{\circ} \mathrm{S}$ to the Cape Verde archipelago. The mean flow field in the upper $1000 \mathrm{~m}$ is characterized by east- and westward current bands (or alternating zonal jets). In general, eastward jets are associated with enhanced oxygen levels and westward jets with reduced oxygen levels. From the scatter in the $\Delta \mathrm{O}_{2}-\Delta S$ relations, we estimated an effective zonal diffusivity that is about 10 times larger than the effective meridional diffusivity. In that calculation, we did not account for advection and the resulting effective zonal diffusivity includes the effect of the alternating zonal jets. Without the effect of alternating zonal jets, the ratio between zonal and meridional diffusivity would be smaller.

The comparison of hydrographic properties for the periods 1972-85 and 1999-2008 revealed the following changes: (i) a decrease of the oxygen concentration in the core of the tropical North Atlantic OMZ of about $15 \mu \mathrm{mol} \mathrm{kg}{ }^{-1}$ and an increase of salinity at the oxygen minimum of about 0.1 ; (ii) a shoaling of oxygen tongues observed at about $5^{\circ}-6^{\circ}$ and $9^{\circ} \mathrm{N}$; (iii) a decrease of the

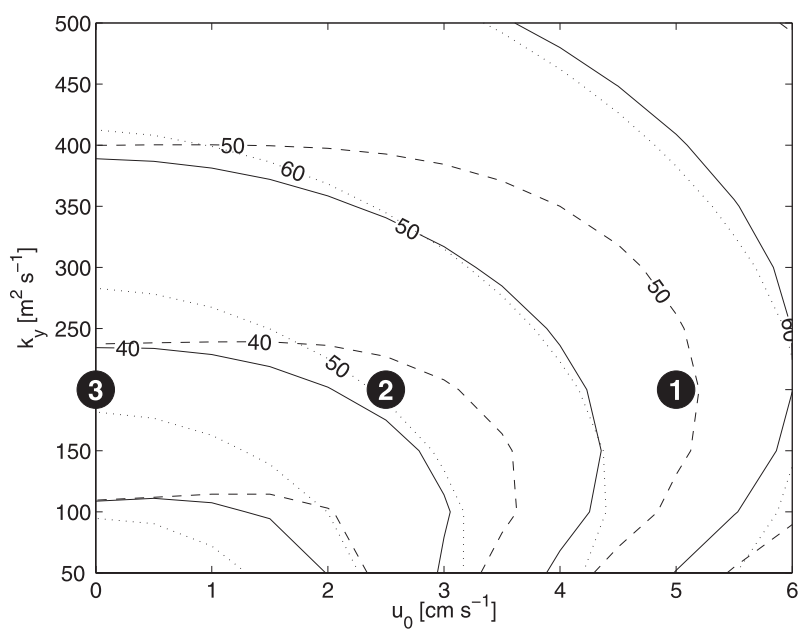

FIG. 14. Absolute oxygen minimum as simulated using Eq. (2) as function of $u_{0}$ and $k_{y}$, with $k_{x}=k_{y}$ (dashed), $k_{x}=2.5 \times k_{y}$ (solid), and $k_{x}=10 \times k_{y}$ (dotted). White characters in black circles mark the parameters of model solutions SIM 1, SIM 2, and SIM 3 plotted in Fig. 13.

oxygen concentration for neutral density levels $\gamma_{n}=$ 26.6-27.3 within the eastward jet at about $9^{\circ} \mathrm{N}$, while the salinity decreased (increased) above (below) $\gamma_{n}=26.9$, respectively; and (iv) a decrease of the scatter in the local $\Delta \mathrm{O}_{2}-\Delta S$ relations.

Stramma et al. (2008b) revealed a negative oxygen trend since 1960 in the 300- to 700-m layer for selected tropical ocean areas. However, the oxygen depletion in the $\mathrm{OMZ}$ of the tropical North Atlantic is about twice as large as in all other tropical regions. Here our new hypothesis is that local circulation changes contribute to long-term changes in the oxygen concentration of the OMZs. One possible explanation for the documented changes in oxygen and salinity on density surfaces between the two analyzed time intervals is that, besides the oxygen depletion common to the OMZs of the World Ocean, in the North Atlantic OMZ a transition occurred from a situation characterized by strong zonal jets to one characterized by weak zonal jets: During 1972-85 a strong eastward jet at about $9^{\circ} \mathrm{N}$ was responsible for the transport of low-salinity oxygen-rich AAIW from the western boundary toward the OMZ below its core. Above the OMZ core, high-saline oxygen-rich North Atlantic Central Water was transported eastward. The existence of a stronger eastward jet during 1972-85 compared to 1999-2008 would also explain the observed increased scatter in the $\Delta \mathrm{O}_{2}-\Delta S$ relations (cf. Figs. 4 and 11) as well as the increased amplitude of the oxygen undulations along the $23^{\circ} \mathrm{W}$ section at $\gamma_{n}=27.1$ (Fig. 8), both are larger than the estimated uncertainty of the observations. Note that the scatter in the $\Delta \mathrm{O}_{2}-\Delta S$ relations represents a filamentation of hydrographic properties 
generated by mesoscale eddies and zonal jets acting on the background hydrographic gradients.

Geostrophic velocities show in general larger amplitudes of latitudinally alternating zonal jets for the period 1972-85 than for the period 1999-2008 (cf. Figs. 2a and $6 a)$. The error of the geostrophic velocity that was estimated to be about $1 \mathrm{~cm} \mathrm{~s}^{-1}$ is mainly due to the larger velocity error at the reference level $(1000 \mathrm{~m})$. Jet amplitudes are likely underestimated in the geostrophic calculation for the later period because of unavoidable horizontal averaging and nonzero velocities at the reference level. Further evidence for the existence of strong jets during 1972-85 and weak jets during 1999-2008 can be found in the different meridional inclinations of the neutral density surface $\gamma_{n}=27.1$ (Fig. $7 d$ ) that is not affected by sparse data coverage at larger depths. During the later period the neutral density surface $\gamma_{n}=27.1$ was flat, while during the earlier period strong undulations can be observed on this density surface.

To determine the necessary changes in the strength of zonal jets or lateral eddy diffusivity that would yield similar changes in the oxygen concentration as observed between the two periods 1972-85 and 1999-2008, we developed a conceptual model for the ventilation and oxygen consumption in the OMZ. The model suggests that the main balance in the OMZ is between oxygen consumption, meridional eddy diffusivity associated with the large-scale oxygen distribution, vertical eddy diffusivity, and advection associated with zonal jets. Zonal jets with amplitudes of 5 and $2.5 \mathrm{~cm} \mathrm{~s}^{-1}$ at the western boundary lead to similar oxygen concentrations in the OMZ and similar amplitudes of oxygen undulations on isopycnal surfaces along $23^{\circ} \mathrm{W}$ between $7^{\circ}$ and $11^{\circ} \mathrm{N}$ as observed for the two periods 1972-85 and 1999-2008, respectively. Assuming that parts of the oxygen depletion since 1960 are due to other processes not studied here would reduce the necessary change in the strength of alternating zonal jets.

Unfortunately, there exist no direct observations of long-term changes in the strength of latitudinally alternating zonal jets or eddy kinetic energy. Therefore, the outlined picture of long-term ventilation changes due to changes in the strength of the zonal jets is based only on the analysis of hydrographic properties and geostrophic velocity calculations. High-resolution model simulations, able to reproduce narrow equatorial zonal current branches and alternating zonal jets in the tropics, could be used to identify possible mechanisms for the suggested changes in the strength of the jets.

A possible explanation for such changes could be the atmospheric and oceanic variability in the Atlantic region on multidecadal time scales that is associated with the Atlantic multidecadal oscillation (AMO). Minimum values of the AMO have been observed during the 1970s with a steady increase afterward. The AMO, typically measured as the sea surface temperature (SST) anomaly of the whole North Atlantic (after subtracting the longterm trend), is thought to be associated with variations in the Atlantic meridional overturning circulation (Knight et al. 2005; Sutton and Hodson 2007). However, the SST variability associated with the AMO represents a differential warming of the Northern Hemisphere compared to the Southern Hemisphere. During high phases of the AMO, the SST gradient from south to north is enhanced (Knight et al. 2005; Sutton and Hodson 2007; Delworth and Mann 2000) and correspondingly the northeasterly (southeasterly) trade winds are found to be reduced (increased; e.g., Foltz and McPhaden 2008). Such wind changes act on similar time scales as the observed changes in the tropical North Atlantic OMZ. As the forcing of latitudinally alternating zonal jets is given by the zonal background flow and associated vertical shear (see, e.g., Berloff et al. 2009), the variability of the Sverdrup circulation in the tropical North Atlantic driven by the cross-equatorial meridional SST gradient (Joyce et al. 2004) represents a likely candidate responsible for changes in the jets' strength.

The proposed reduction of the OMZ ventilation because of a weakening of latitudinally alternating zonal jets adds a further mechanism to the list of biogeochemical and physical mechanisms that could explain the ongoing oxygen depletion in the tropical North Atlantic. The detection of anthropogenic climate change in the available observational record of oceanic oxygen distribution, however, strongly depends on a quantitative understanding of intrinsic and anthropogenic oxygen variability on decadal to multidecadal time scales.

Acknowledgments. We thank Carsten Eden and Marcus Dengler for helpful discussions. This study was supported by the Deutsche Forschungsgemeinschaft as part of the Sonderforschungsbereich 754 "ClimateBiogeochemistry Interactions in the Tropical Ocean" and by the German Federal Ministry of Education and Research as part of the cooperative project "Nordatlantik."

\section{APPENDIX}

\section{Geostrophic Velocities and Associated Errors}

The geostrophic zonal velocities shown in Fig. 6a are deduced using the mean temperature $T$ and salinity $S$ distributions along $\sim 23^{\circ} \mathrm{W}$ for the period $1972-85$. At each latitudinal grid point, we calculated the geopotential anomaly $\Phi$ as the integral of the specific volume 


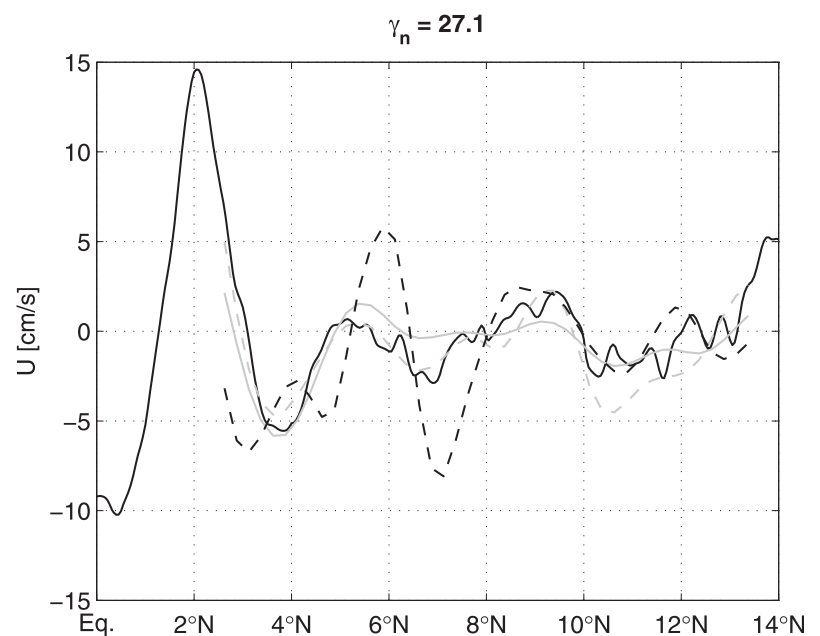

FIG. A1. Mean zonal velocity on $\gamma_{n}=27.1$ along $\sim 23^{\circ} \mathrm{W}$. Solid black line: absolute velocity from direct current observations for the period 1999-2008; solid and dashed gray lines: geostrophic velocities referenced to a level of no motion at $1000 \mathrm{~m}$ and referenced to a level of known motion at 950-1000 m (absolute velocity) for the period 1999-2008, respectively; dashed black line: geostrophic velocity referenced to a level of no motion at $1000 \mathrm{~m}$ for the period 1972-85.

anomaly $\delta$ from the pressure $p$ to the pressure at the reference level $p_{\text {ref }}$ (i.e., at $1000 \mathrm{~m}$ ):

$$
\Phi(p)=\int_{p}^{p_{\mathrm{ref}}} \delta d p^{\prime} .
$$

The resulting field is smoothed by a running mean of width $1.25^{\circ}$ in latitude and geostrophic velocities are calculated between two grid points A and B separated by $\Delta y$.

Likewise, we determined comparable geostrophic zonal velocities along $\sim 23^{\circ} \mathrm{W}$ for the period $1999-2008$ after first reducing the higher horizontal and vertical resolution of the mean fields (see Fig. 2) to the same resolution of the historical dataset. In addition to Fig. 7a, we present in Fig. A1 two differently referenced geostrophic velocities on the neutral density surface $\gamma_{n}=$ 27.1 for the period 1999-2008: (i) level of no motion at $1000 \mathrm{~m}$ (as used for the period 1972-85), and (ii) level of known motion at 950-1000 $\mathrm{m}$ (as determined from the absolute zonal velocities from direct current observations presented in Fig. 2a). The comparison of these differently referenced geostrophic velocities with the absolute zonal velocities indicates that the assumption of a level of no motion at $1000 \mathrm{~m}$ is in general not valid. The strength of latitudinally alternating zonal jets may be underestimated when using a level of no motion at $1000 \mathrm{~m}$, which could be conjectured from recent float observations showing significant jet amplitudes at 1000-m
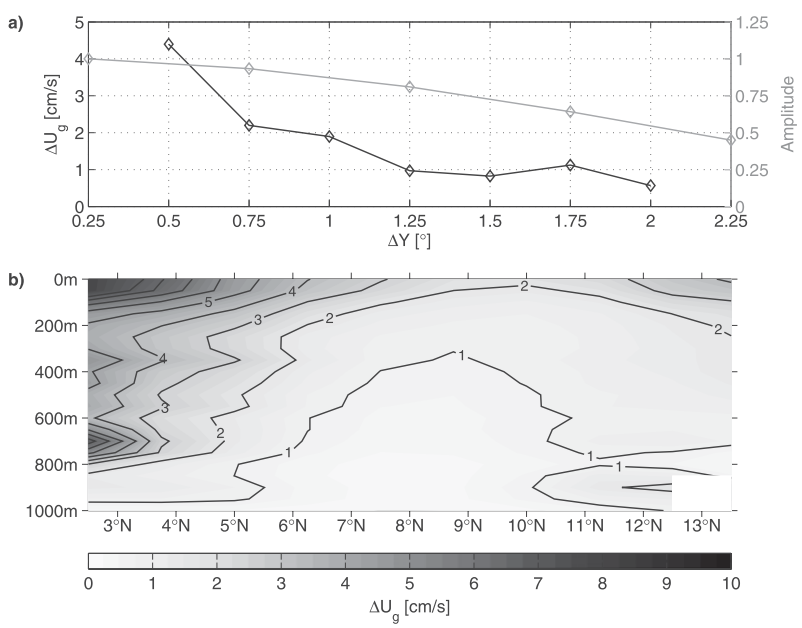

FIG. A2. (a) Error of geostrophic velocity referenced to $1000 \mathrm{~m}$ (or to deepest available grid box) averaged between $7^{\circ}-11^{\circ} \mathrm{N}$ and $300-500 \mathrm{~m}$ for the period $1972-85$ as a function of meridional spacing $\Delta y$ (black) and relative amplitude of latitudinally alternating zonal jets that are defined by a cosine function with a wavelength of $3.5^{\circ}$ in latitude after applying different running mean widths $\Delta y$ (gray). (b) Distribution of the error of the geostrophic velocity referenced to $1000 \mathrm{~m}$ along $\sim 23^{\circ} \mathrm{W}$ for a meridional spacing of $1.25^{\circ}$ in latitude.

depth (Ollitrault et al. 2006). North of $10^{\circ} \mathrm{N}$, the larger differences between absolute zonal velocities and geostrophic velocities referenced to a level of known motion at 950-1000 $\mathrm{m}$ are likely due to the smaller number of available shipboard sections in this region (see Table 1) and large oceanic variability directly south of the Cape Verde archipelago that are associated with larger standard errors of both absolute and geostrophic velocities.

Besides the uncertainty due to the choice of the reference level, the geopotential anomalies are prone to errors in temperature and salinity. To estimate the resulting error in the geostrophic velocity for the period 1972-85, we calculated from individual $T-S$ profiles box averages of geopotential anomalies [according to Eq. (A1)] and their standard error $\Delta \Phi$ along $\sim 23^{\circ} \mathrm{W}$ for vertical box sizes of $50 \mathrm{~m}$ and different meridional box sizes $\Delta y$. The error of the geostrophic velocity referenced to $1000 \mathrm{~m}$, calculated from adjacent boxes $\mathrm{A}$ and $\mathrm{B}$, is given by

$$
\Delta u_{g}=\frac{1}{f \Delta y} \sqrt{\left(\Delta \Phi_{A}\right)^{2}+\left(\Delta \Phi_{B}\right)^{2}}
$$

where $f$ is the Coriolis parameter. The error of the geostrophic velocity near the core of the OMZ; that is, averaged between $7^{\circ}-11^{\circ} \mathrm{N}$ and $300-500 \mathrm{~m}$, decreases with increasing $\Delta y$ and it is about $1 \mathrm{~cm} \mathrm{~s}^{-1}$ for $\Delta y=1.25^{\circ}$ in latitude (Fig. A2a). To illustrate the damping effect of a running mean (of width $\Delta y$ ) on the amplitude of latitudinally alternating zonal jets, we used a simple cosine 
function with a meridional wavelength of $3.5^{\circ}$ in latitude. The jet amplitude reduces with increasing $\Delta y$, for $\Delta y=$ $1.25^{\circ}$ the amplitude is at about $80 \%$ of its original value. The geostrophic velocity error [Eq. (A2)] increases with distance from the reference level. It is larger in regions with sparse data coverage and large oceanic variability (northern part of the region) and close to the equator due to the $f$ dependence of the error (Fig. A2b).

\section{REFERENCES}

Armi, L., and H. Stommel, 1983: Four views of a portion of the North Atlantic subtropical gyre. J. Phys. Oceanogr., 13, 828-857.

Athie, G., and F. Marin, 2008: Cross-equatorial structure and temporal modulation of intraseasonal variability at the surface of the Tropical Atlantic Ocean. J. Geophys. Res., 113, C08020, doi:10.1029/2007JC004332.

Berloff, P., I. Kamenkovich, and J. Pedlosky, 2009: A model of multiple zonal jets in the oceans: Dynamical and kinematical analysis. J. Phys. Oceanogr., 39, 2711-2734.

Boebel, O., R. E. Davis, M. Ollitrault, R. G. Peterson, P. L. Richardson, C. Schmid, and W. Zenk, 1999: The intermediate depth circulation of the western South Atlantic. Geophys. Res. Lett., 26, 3329-3332.

Bopp, L., C. Le Quéré, M. Heimann, A. C. Manning, and P. Monfray, 2002: Climate-induced oceanic oxygen fluxes: Implications for the contemporary carbon budget. Global Biogeochem. Cycles, 16, 1022, doi:10.1029/2001GB001445.

Bourlès, B., M. d'Orgeville, G. Eldin, Y. Gouriou, R. Chuchla, Y. du Penhoat, and S. Arnault, 2002: On the evolution of the thermocline and subthermocline eastward currents in the Equatorial Atlantic. Geophys. Res. Lett., 29, 1785, doi:10.1029/ 2002GL015098.

Boyer, T. P., J. I. Antonov, S. Levitus, and R. Locarnini, 2005: Linear trends of salinity for the world ocean, 1955-1998. Geophys. Res. Lett., 32, L01604, doi:10.1029/2004GL021791.

Brandt, P., F. A. Schott, C. Provost, A. Kartavtseff, V. Hormann, B. Bourlès, and J. Fischer, 2006: Circulation in the central equatorial Atlantic: Mean and intraseasonal to seasonal variability. Geophys. Res. Lett., 33, L07609, doi:10.1029/ 2005GL025498.

_ V. V. Hormann, B. Bourlès, J. Fischer, F. A. Schott, L. Stramma, and M. Dengler, 2008: Oxygen tongues and zonal currents in the equatorial Atlantic. J. Geophys. Res., 113, C04012, doi:10.1029/2007JC004435.

Brewer, P. G., and E. T. Peltzer, 2009: Limits to marine life. Science, 324 (5925), 347-348.

Chan, F., J. A. Barth, J. Lubchenco, A. Kirincich, H. Weeks, W. T. Peterson, and B. Menge, 2008: Emergence of anoxia in the California Current large marine ecosystem. Science, 319, 920.

Curry, R., B. Dickson, and I. Yashayaev, 2003: A change in the freshwater balance of the Atlantic Ocean over the past four decades. Nature, 426, 826-829.

Delworth, T. L., and M. E. Mann, 2000: Observed and simulated multidecadal variability in the northern hemisphere. Climate Dyn., 16, 661-676.

Eden, C., 2006: Middepth equatorial tracer tongues in a model of the Atlantic Ocean. J. Geophys. Res., 111, C12025, doi:10.1029/ $2006 \mathrm{JC} 003565$. and R. J. Greatbatch, 2008: Diapycnal mixing by mesoscale eddies. Ocean Modell., 23 (3-4), 113-120.

— - — , and J. Willebrand, 2007: A diagnosis of thickness fluxes in an eddy-resolving model. J. Phys. Oceanogr., 37, 727-742.

Ferrari, R., and K. L. Polzin, 2005: Finescale structure of the $T-S$ relation in the eastern North Atlantic. J. Phys. Oceanogr., 35, 1437-1454.

Fischer, J., P. Brandt, M. Dengler, M. Müller, and D. Symonds, 2003: Surveying the upper ocean with the Ocean Surveyor: A new phased array Doppler current profiler. J. Atmos. Oceanic Technol., 20, 742-751.

Foltz, G. R., and M. J. McPhaden, 2008: Trends in Saharan dust and tropical Atlantic climate during 1980-2006. Geophys. Res. Lett., 35, L20706, doi:10.1029/2008GL035042.

Gnanadesikan, A., J. L. Russell, and F. Zeng, 2007: How does ocean ventilation change under global warming? Ocean Sci., $\mathbf{3}$, $43-53$

Gouretski, V. V., and K. P. Koltermann, 2004: WOCE Global Hydrographic Climatology. Tech. Rep. 35, Bundesamt für Seeschifffahrt und Hydrographie, Hamburg, Germany, 52 pp.

Hofmann, M., and H.-J. Schellnhuber, 2009: Oceanic acidification affects marine carbon pump and triggers extended marine oxygen holes. Proc. Natl. Acad. Sci. USA, 106, 3017-3022.

Johnson, G. C., and N. Gruber, 2007: Decadal water mass variations along $20^{\circ} \mathrm{W}$ in the Northeastern Atlantic Ocean. Prog. Oceanogr., 73, 277-295.

Joos, F., G.-K. Plattner, T. F. Stocker, A. Körtzinger, and D. W. R. Wallace, 2003: Trends in marine dissolved oxygen: Implications for ocean circulation changes and carbon budget. Eos, Trans. Amer. Geophys. Union, 84, 197.

Joyce, T. M., J. R. Luyten, A. Kubryakov, F. B. Bahr, and J. S. Pallant, 1998: Meso- to large-scale structure of subducting water in the subtropical gyre of the eastern North Atlantic Ocean. J. Phys. Oceanogr., 28, 40-61.

— C. Frankignoul, J. Yang, and H. E. Phillips, 2004: Ocean response and feedback to the SST dipole in the Tropical Atlantic. J. Phys. Oceanogr., 34, 2525-2540.

Karstensen, J., L. Stramma, and M. Visbeck, 2008: The oxygen minimum zones in the eastern tropical Atlantic and Pacific oceans. Prog. Oceanogr., 77, 331-350.

Keeling, R. F., A. Körtzinger, and N. Gruber, 2010: Ocean deoxygenation in a warming world. Annu. Rev. Mater. Sci., 2, 463-493.

Kirchner, K., M. Rhein, S. Hüttl-Kabus, and C. W. Böning, 2009: On the spreading of South Atlantic Water into the northern hemisphere. J. Geophys. Res., 114, C05019, doi:10.1029/ 2008JC005165.

Knight, J. R., R. J. Allan, C. K. Folland, M. Vellinga, and M. E. Mann, 2005: A signature of persistent natural thermohaline circulation cycles in observed climate. Geophys. Res. Lett., 32, L20708, doi:10.1029/2005GL024233.

Ledwell, J. R., A. J. Watson, and C. S. Law, 1993: Evidence for slow mixing across the pycnocline from an open-ocean tracerrelease experiment. Nature, 364, 701-703.

,-- , and -1998 : Mixing of a tracer in the pycnocline. J. Geophys. Res., 103, 21 499-21 529.

Luyten, J. R., J. Pedlosky, and H. Stommel, 1983: The ventilated thermocline. J. Phys. Oceanogr., 13, 292-309.

Matear, R. J., and A. C. Hirst, 2003: Long-term changes in dissolved oxygen concentrations in the ocean caused by protracted global warming. Global Biogeochem. Cycles, 17, 1125, doi:10.1029/2002GB001997. 
Maximenko, N. A., B. Bang, and H. Sasaki, 2005: Observational evidence of alternating zonal jets in the world ocean. Geophys. Res. Lett., 32, L12607, doi:10.1029/2005GL022728.

Mittelstaedt, E., 1983: The upwelling area off Northwest Africa. A description of phenomena related to coastal upwelling. Prog. Oceanogr., 12, 307-331.

Nakano, H., and H. Hasumi, 2005: A series of zonal jets embedded in the broad zonal flows in the Pacific obtained in eddypermitting ocean general circulation models. J. Phys. Oceanogr., 35, 474-488.

Ollitrault, M., M. Lankhorst, D. Fratantoni, P. Richardson, and W. Zenk, 2006: Zonal intermediate currents in the equatorial Atlantic Ocean. Geophys. Res. Lett., 33, L05605, doi:10.1029/ 2005 GL025368.

Oschlies, A., K. G. Schulz, U. Riebesell, and A. Schmittner, 2008: Simulated 21st century's increase in oceanic suboxia by $\mathrm{CO}_{2-}$ enhanced biotic carbon export. Global Biogeochem. Cycles, 22, GB4008, doi:10.1029/2007GB003147.

Richards, K. J., N. A. Maximenko, F. O. Bryan, and H. Sasaki, 2006: Zonal jets in the Pacific Ocean. Geophys. Res. Lett., 33, L03605, doi:10.1029/2005GL024645.

Schott, F. A., L. Stramma, and J. Fischer, 1995: The warm water inflow into the western tropical Atlantic boundary regime, spring 1994. J. Geophys. Res., 100C, 24 745-24 760.
Stramma, L., P. Brandt, J. Schafstall, F. Schott, J. Fischer, and A. Körtzinger, 2008a: Oxygen minimum zone in the North Atlantic south and east of the Cape Verde Islands. J. Geophys. Res., 113, C04014, doi:10.1029/2007JC004369.

G. C. Johnson, J. Sprintall, and V. Mohrholz, 2008b: Expanding oxygen-minimum zones in the tropical oceans. Science, 320, 655-658.

Sutton, R. T., and D. L. R. Hodson, 2007: Climate response to basin-scale warming and cooling of the North Atlantic Ocean. J. Climate, 20, 891-907.

Tsuchiya, M., L. D. Talley, and M. S. McCartney, 1992: An eastern Atlantic section from Iceland southward across the equator. Deep-Sea Res., 39, 1885-1917.

van Geen, A., W. M. Smethie Jr., A. Horneman, and H. Lee, 2006: Sensitivity of the North Pacific oxygen minimum zone to changes in ocean circulation: A simple model calibrated by chlorofluorocarbons. J. Geophys. Res., 111, C10004, doi:10.1029/ 2005JC003192.

Visbeck, M., 2002: Deep velocity profiling using lowered acoustic Doppler current profilers: Bottom track and inverse solutions. J. Atmos. Oceanic Technol., 19, 794-807.

von Schuckmann, K., P. Brandt, and C. Eden, 2008: Generation of tropical instability waves in the Atlantic Ocean. J. Geophys. Res., 113, C08034, doi:10.1029/2007JC004712. 